\title{
EXPERIMENTAL STUDY INTO THE BEHAVIOUR OF PROFILED COMPOSITE WALLS UNDER COMBINED AXIAL AND THERMAL LOADINGS
}

\author{
Quang X. Le ${ }^{1,4}$, Vinh T.N. Dao ${ }^{1 *}$, Jose L. Torero ${ }^{2}$ and Tuan D. $\mathrm{Ngo}^{3}$ \\ ${ }^{1}$ School of Civil Engineering, The University of Queensland, Brisbane, QLD 4072, Australia \\ ${ }^{2}$ Department of Civil, Environmental and Geomatic Engineering, University College London, UK \\ ${ }^{3}$ Department of Infrastructure Engineering, The University of Melbourne, VIC 3052, Australia \\ ${ }^{4}$ Faculty of Civil Engineering, The University of Danang - University of Science and Technology, Danang, Vietnam
}

\begin{abstract}
Profiled composite walls (PCWs) are regularly used in construction because they provide enhanced ductility, shear resistance and damage tolerance when compared to traditional reinforced concrete walls. Although much research has been conducted to understand the structural performance of PCWs at ambient temperature, studies into their performance at high temperatures remain limited. In this work, a comprehensive set of experiments has been conducted to investigate the performance of PCWs at both ambient and elevated temperatures. A heat source comprising of radiant burners and 1MN MTS machine were employed to deliver known and actively controlled thermal and structural boundary conditions on the PCW samples. The experiments were conducted to understand the effects of an incident heat flux when combined with loads. The results from this study have shown that (i) the axial load capacity of PCWs decreases as the temperature increases; (ii) the PCWs tends to exhibit ductile failure modes when cold but brittle failure at high temperature; (iii) due to thermal bowing, the failure plane of the PCWs subjected to one-side heating shifts closer to the heating source; and (iv) applying a load in an eccentric manner can compensate for the effect of temperature gradient.
\end{abstract}

Keywords: temperature gradient, failure modes, failure plane, axial load capacity, profiled composite wall.

\section{NOMENCLATURE}

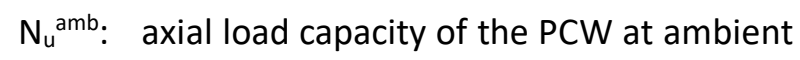
temperature $(\mathrm{kN})$;

$\mathrm{N}_{\mathrm{uc}}{ }^{\mathrm{amb}}$ : axial load capacity of the concrete core at ambient temperature $(\mathrm{kN})$;

$\mathrm{Nus}_{\mathrm{umb}}^{\text {amb }}$ axial load capacity of the steel sheet at ambient temperature $(\mathrm{kN})$;
30 P20:

31 P40:

32 E10:

33 axis;

34 HF42: incident heat flux of $42 \mathrm{~kW} / \mathrm{m}^{2}$;

35 HF60: incident heat flux of $60 \mathrm{~kW} / \mathrm{m}^{2}$;

\section{INTRODUCTION}

Profiled composite walls (PCWs) were developed as a variant of the concept of using a profiled steel sheet in a flooring system $[1,2]$. PCWs consist of two skins of profiled steel sheets with an in-fill concrete core. The composite interaction between the steel sheets and concrete core can be enhanced through the use of (i) the crest and embossment system on steel sheets and (ii) intermediate fasteners [3]. Compared to a traditional reinforced wall with similar load-carrying capacity, a PCW is typical of smaller thickness and lighter, thereby reducing the total dead load on the foundation [4]. Besides, PCWs are ductile and exhibit higher shear resistance and better damage tolerance in the concrete core during service [3]. It is clear that PCWs can replace traditional reinforced concrete walls as structural elements to withstand various loadings (axial, cyclic, lateral, impact or combined loadings).

Research in the performance of PCWs at ambient temperature has been widely conducted using experimental, analytical and numerical studies [1, 2, 5-13]. Wright [9] conducted 13 tests to investigate the axial behaviour of PCWs, and demonstrated the efficiency of PCWs compared to conventional reinforced walls in terms of stability and the prevention of global buckling. Similarly, Hossain and Wright [11] conducted several tests on PCWs with normal strength concrete infill under cyclic loading to highlight the effects of using 
embossment and intermediate bolts on the shear interaction between the profiled steel skins and concrete core. The enhanced structural performance of PCW's over the conventional reinforced wall at ambient temperatures $[1,2,7]$ has resulted in this type of composite wall being used as not only non-load-bearing but also load-bearing elements in low-rise residential, industrial and high-rise buildings $[1,6,13]$. A further advantage of PCWs is that the steel sheets can act as permanent formwork during the construction stage, thereby reducing the time and cost associated with the labour-intensive construction [2]. Thus, PCWs enhance the speed of construction without compromising structural performance at ambient temperatures [9].

In many cases, non-load bearing and load bearing walls are required to deliver structural performance in the event of a fire. The expectation for a wall is that they will contain the fire by remaining undamaged and fulfilling their intended function. Thus, the relevant objective is to retain adequate performance while subjected to one side heating. Despite this requirement, research on thermal behaviour as well as on understanding the combined thermal and structural behaviour of PCWs remains somewhat limited $[3,7,13$ 15]. The report by $\mathrm{Hu}$ and Nicholls [16] indicates that the structural performance of prefabricated PCWs at high temperatures has been neglected in fire tests. Consequently, the true structural performance of such PCWs at high temperature remains largely unknown.

Study conducted by Taormina and Hossain [14] seems the only experimental research that investigated the structural behaviour of PCWs at elevated temperatures. In their experimental program, the residual load capacity, load-deflection behaviour, concrete cracking, buckling of the steel sheets and overall failure modes were explored in a systematic manner. Their paper reveals similar behaviour at an elevated temperature between PCWs and other concrete/steel composite systems; nevertheless, their findings remain essentially qualitative.

Other studies exploring the high temperature performance of concrete/steel composite systems such as concrete-filled steel tubular columns have established different areas of potential interest for PCWs. During the heating process, the gap between the steel sheet and concrete core is believed to significantly affect the performance of these composite systems at elevated temperatures [17]. A change in gap size influences not only the heat transfer between the steel sheets and the concrete core but also the buckling of the steel sheets and the confinement to the concrete core. Therefore, neglecting the effect of the gap conductance and gap size can lead to an inaccurate estimation of the temperature and temperature gradient in the composite wall, and consequently, an incorrect prediction of its structural fire performance [17-19]. These effects remain inadequately examined and quantified for PCWs.

When subjected to high temperatures, the properties of both steel and concrete are generally reduced at different rates [20]. Furthermore, the difference in the expansion behaviour of both concrete and steel materials under a combination of thermal and structural loads introduces coupled effects of stress and thermal expansion that potentially govern the overall stress and strain development [21]. Again, such effects have not been properly examined and quantified for PCWs.

The temperature gradient within the cross-section may shift the effective centroid towards the colder region, thus increasing the bowing of the sample towards the heating source. These effects have been shown to result in different failure modes at elevated temperatures for other types of structural systems [22, 23]. However, there have been no reported studies that properly consider these combined effects on PCWs.

The experimental study reported in this paper sought to understand and quantify the structural behaviour of PCWs when subjected to combined axial and thermal loadings. A unique novel test setup was used in this research, including (i) reliable structural boundary condition using 1MN MTS machine, (ii) reliable thermal boundary condition using a novel burner system, and (iii) reliable thermal-structural information captured throughout the testing process. The data collected were analysed to examine and quantify the effects of combined axial and thermal loadings on PCWs. 
99

100

\subsection{Samples preparation}

Normal strength concrete with a 28-day compressive strength of $25 \mathrm{MPa}$ was used as the in-fill material for the PCWs. The binder was Ordinary Portland Cement, and the maximum aggregate size was $10 \mathrm{~mm}$. Cylindrical samples were cured under the same conditions as the test samples to ensure consistency of the concrete properties at ambient temperature.

Cold-rolled mild steel with a thickness of $0.95 \mathrm{~mm}$ was used to fabricate the steel sheets. The steel sheet has a tensile yield strength of $280 \mathrm{MPa}$ and Young's modulus of $200000 \mathrm{MPa}$. All mixing and casting were conducted in accordance with Australian standards [24, 25].

After casting, the samples were kept moist continuously by covering with damp cloths. At seven days after casting, the PCW samples were de-moulded and wrapped in plastic to ensure negligible moisture exchange between the concrete and surrounding environment. The PCW samples were then wrapped until the testing day.

Nineteen small-scaled PCWs, with nominal dimensions of $290 \mathrm{~mm}$ (width) $\times 400 \mathrm{~mm}$ (height) $\times 80 \mathrm{~mm}$ (thickness), were designed to behave as short walls, as shown in Fig. 1. Two crests on a steel sheet with dimensions of $25 \mathrm{~mm} \times 20 \mathrm{~mm} \times 15 \mathrm{~mm}$ (Figs 1 and 2)were made to create a self-interlocking mechanism between the concrete and steel sheet after casting.

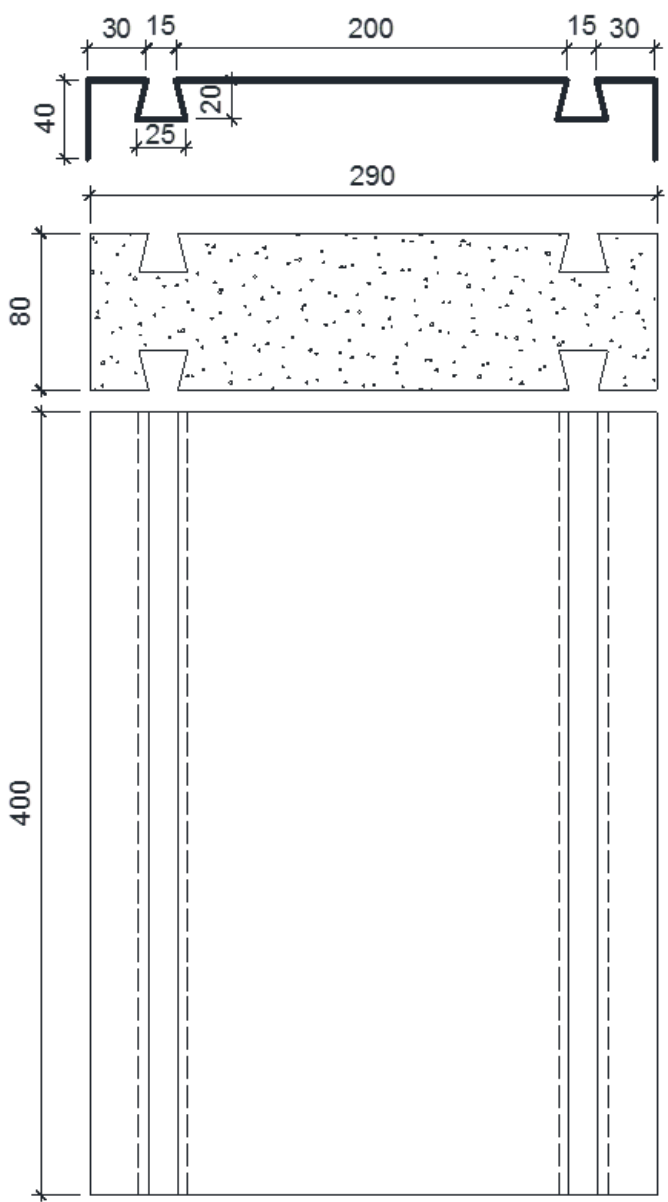

Fig. 1. Details of profiled composite wall. 


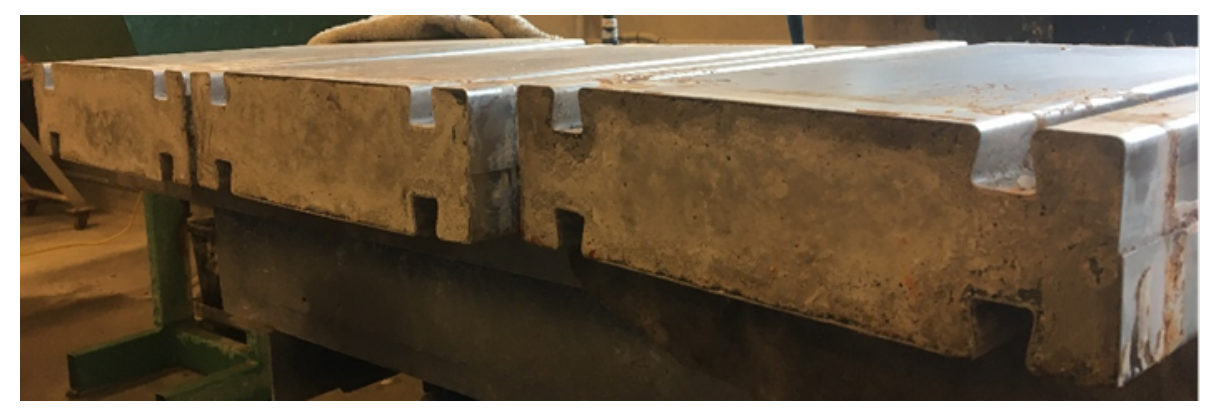

Fig. 2. Photo of samples Series 2.

\subsection{The experimental setup}

\subsubsection{Mechanical loading system}

Fig. 3 shows a schematic of the compression tests conducted on the PCW samples. The critical components of the setup are summarised as follows:

- A 1MN MTS machine was used to generate compressive loads with two water-cooled systems above and below the test specimens.

- Two spherical seats were located at the top and bottom of the samples to generate the pinnedpinned supports.

- During testing, the data were recorded by a data logger embedded in the MTS testing machine.

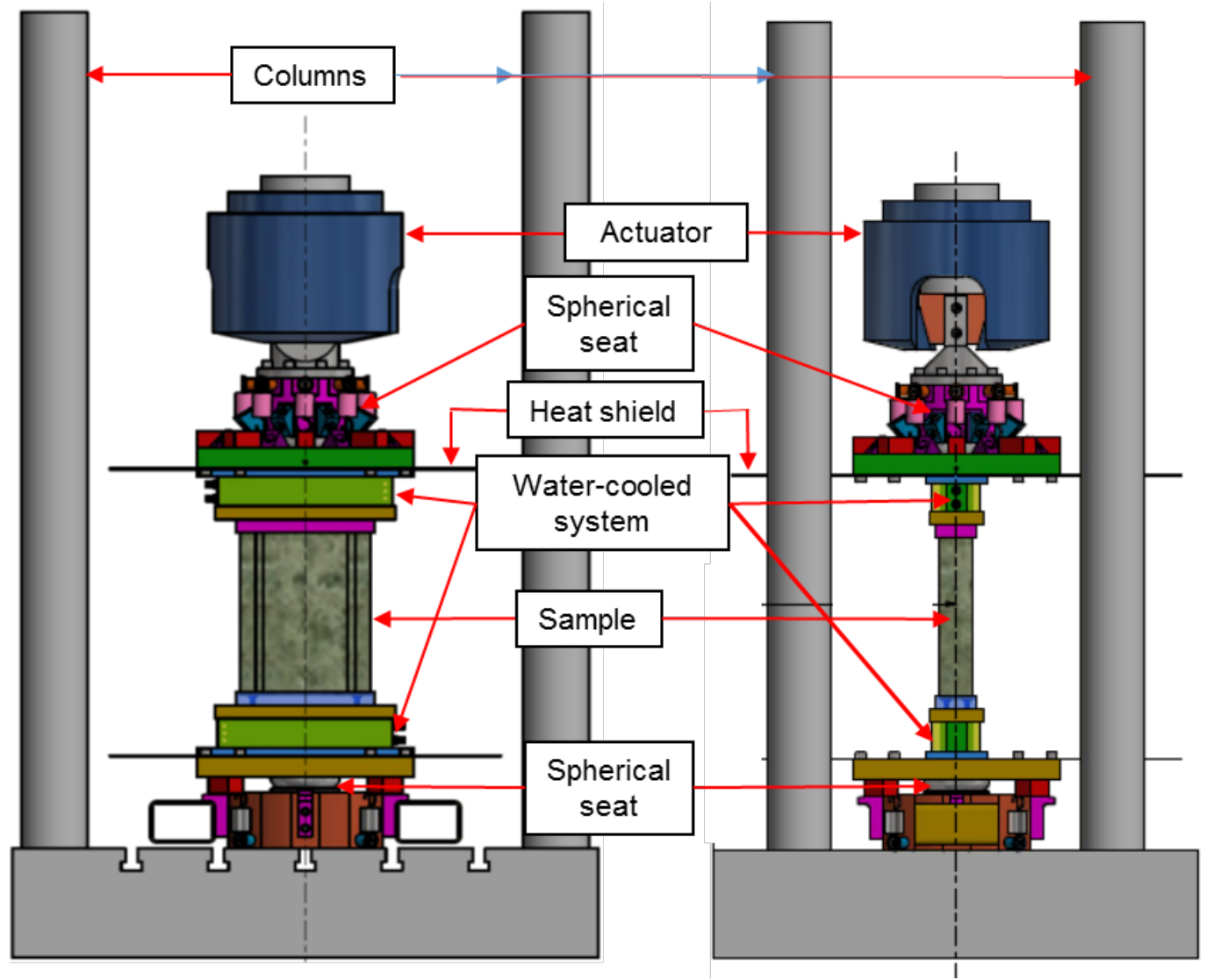

a) Front view

b) Side view

Fig. 3. Mechanical loading test setup.

\subsubsection{Compressive loading at different eccentricities}

Fig. 4 is a schematic of the setup for applying compressive loading at zero and 10-mm eccentricity on the samples. Two stainless steel caps, placed at the top and bottom of the samples, are bolted to the watercooled platens. 


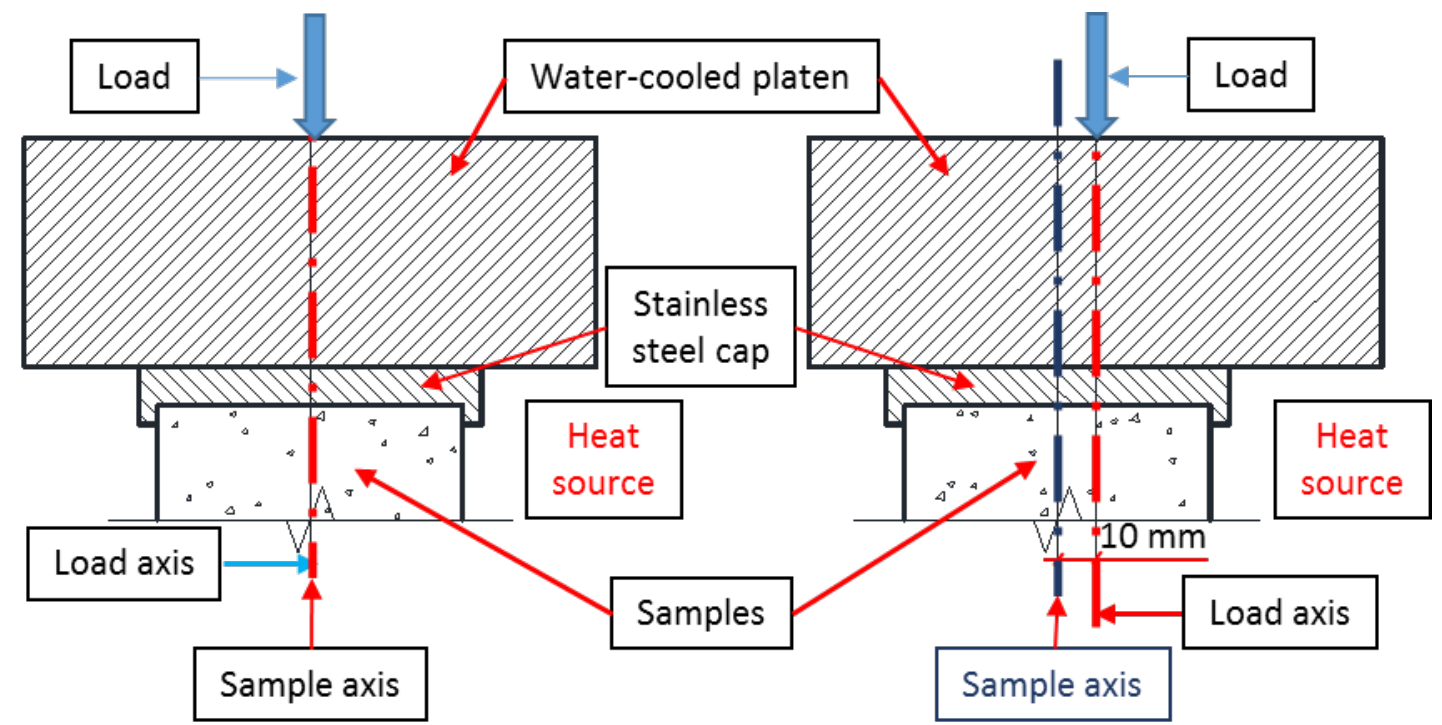

a) Zero eccentricity

b) $10-\mathrm{mm}$ eccentricity

Fig. 4. Details for applying compressive loading at different eccentricities.

\subsubsection{Radiant panels and heat flux calibration}

The incident heat flux on the surface of each sample was controlled by using a set of four small radiant panels, as shown in Fig. 5. The burner system has a width of $300 \mathrm{~mm}$ and a height of $400 \mathrm{~mm}$. The consistency and repeatability of the incident heat fluxes generated by this system have been established and reported [2628]. The target incident heat fluxes were chosen at $42 \mathrm{~kW} / \mathrm{m}^{2}$ and $60 \mathrm{~kW} / \mathrm{m}^{2}$ in this study, based on reported values for typical compartment fires [29].

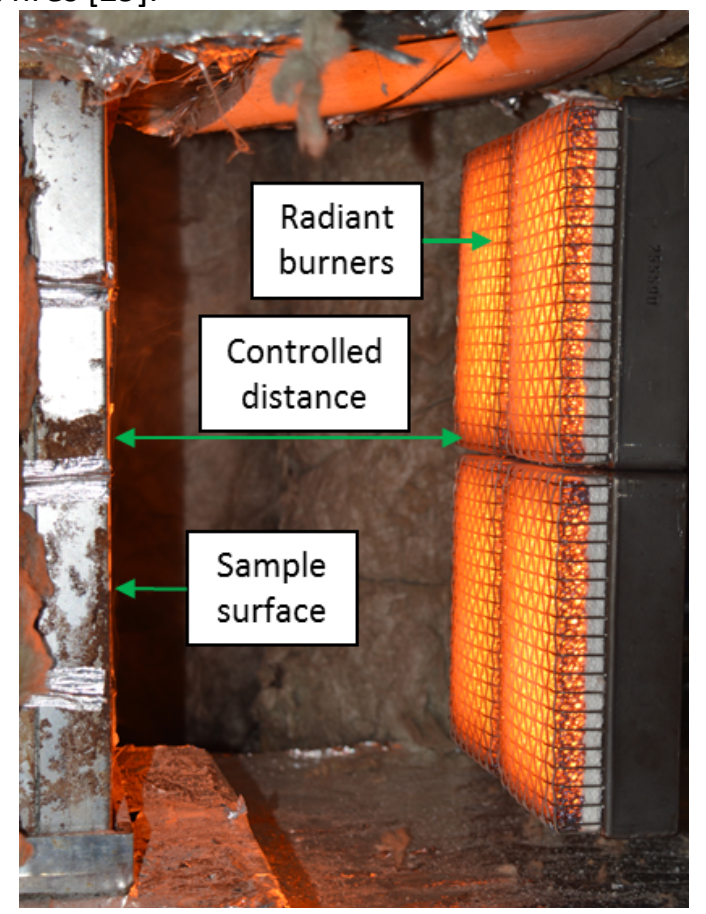

Fig. 5. Radiant burners and test sample.

The heat-flux was calibrated using a Schmidt-Boelter sensor using the following procedure:

- The Schmidt-Boelter heat flux sensor was placed along the axis going through the centre of and perpendicular to the radiant panel (Point A in Fig. 6(a)). The distance between the burners and the calibration plane was then adjusted to obtain the incident heat flux profile as a function of distance. As shown in Fig. $6(\mathrm{~b})$, for the incident heat fluxes of $42 \mathrm{~kW} / \mathrm{m}^{2}$ (HF42) and $60 \mathrm{~kW} / \mathrm{m}^{2}$ (HF60), the corresponding distance was determined as $31.0 \mathrm{~cm}$ and $24.7 \mathrm{~cm}$, respectively. These distances were used for corresponding samples in subsequent tests. 
- To assess the possible non-uniformity of the heat flux distribution on the surface of each sample, the incident heat flux was also measured at eight other points beside the central point, as shown in Fig. 6(a). A heat flux map (Fig. 7) was produced for both heat fluxes of interest (HF42 and HF60), showing that the samples were heated in a symmetric manner and within a range of $\pm 5 \mathrm{~kW} / \mathrm{m}^{2}$ from the average value for more than $80 \%$ of the sample area.

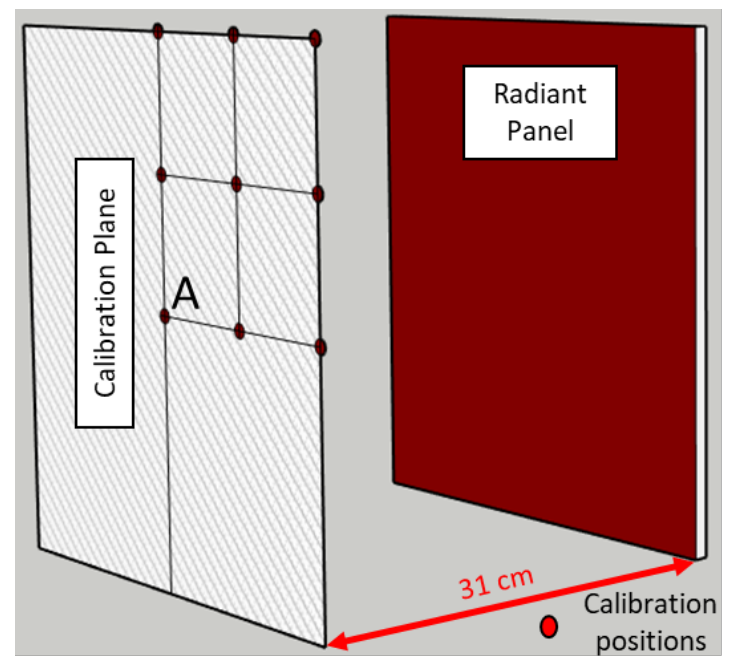

a) Burner and its calibrated positions

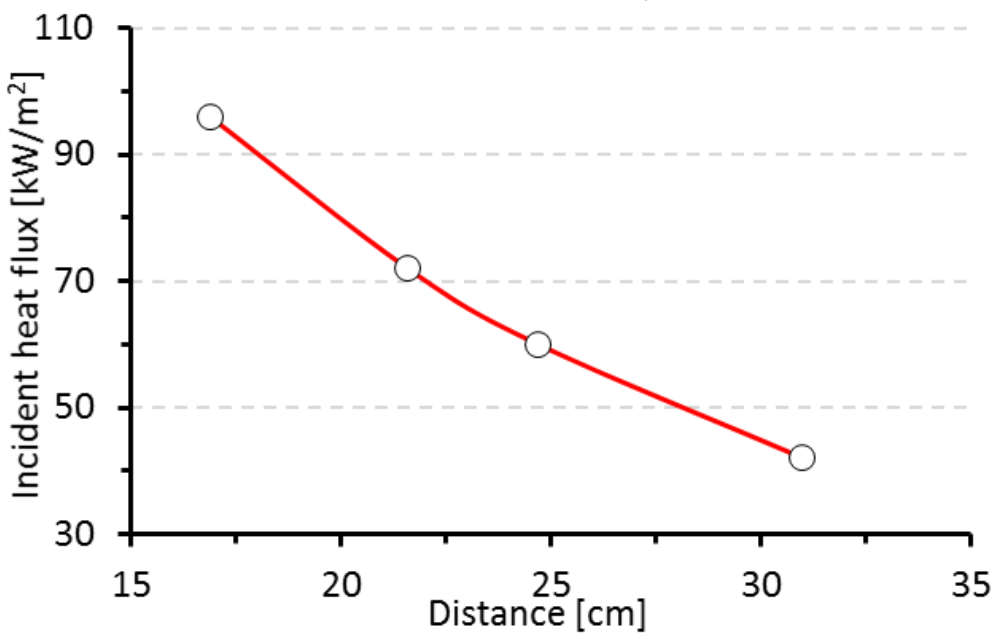

b) Variation of incident heat flux with distance from the surface of the burner

Fig. 6. Heat flux calibration procedure and results.

\subsubsection{Water-cooled and thermal insulation system}

Due to the small size of the test sample and its proximity to the radiant panel system, the distance between the MTS actuator and the radiant panel system was less than $300 \mathrm{~mm}$. The heat transferred from the radiant panels by convection and radiation, and from the samples by conduction, can compromise the MTS actuator, the oil temperature of which is required to be lower than $40^{\circ} \mathrm{C}$. Also, too high temperature increase can result in excessive thermal expansion of the MTS actuator and MTS columns, compromising the quality of the obtained data. It is thus critical to provide proper thermal insulation to ensure that the MTS actuator and columns remain at below $40^{\circ} \mathrm{C}$. 


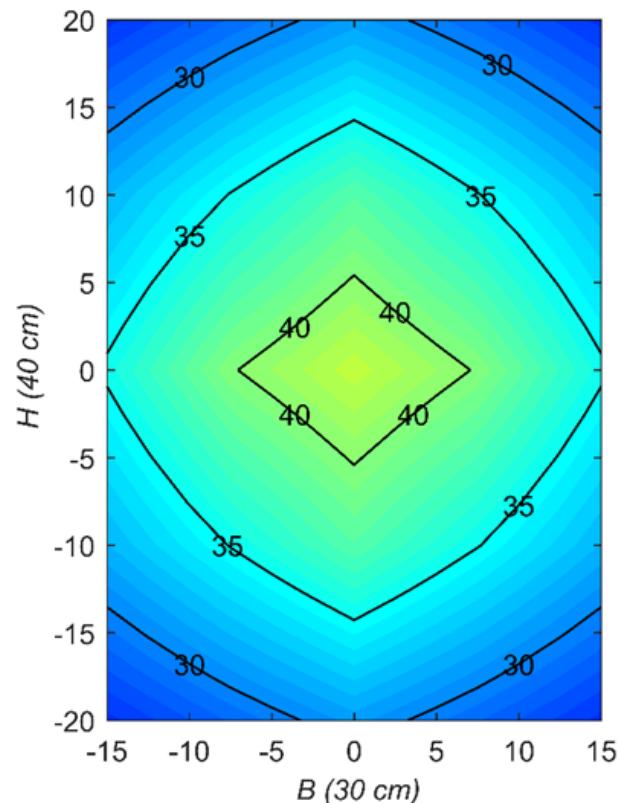

a) For $42 \mathrm{~kW} / \mathrm{m}^{2}$

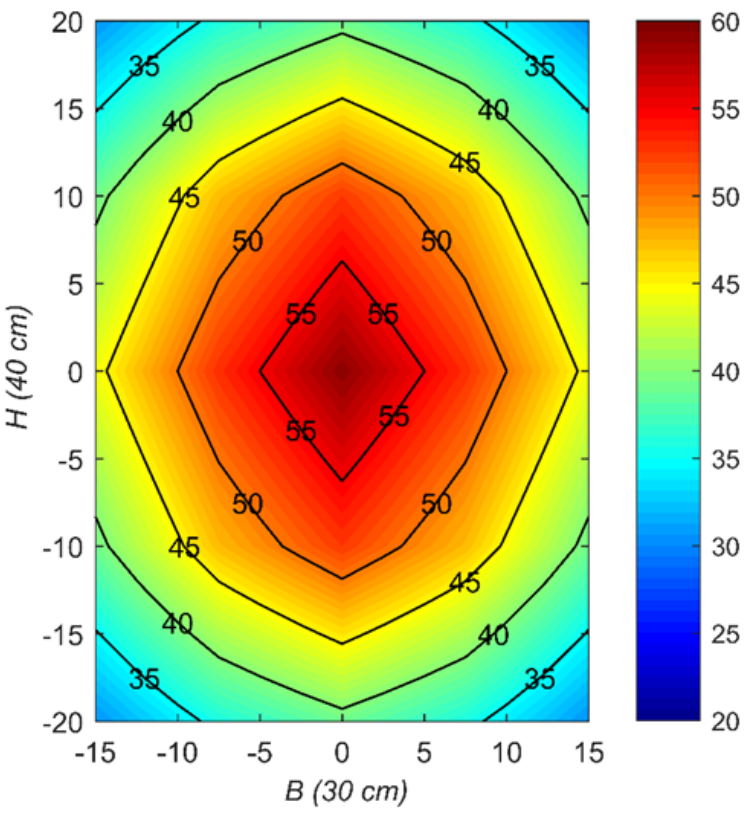

b) For $60 \mathrm{~kW} / \mathrm{m}^{2}$

Fig. 7. Incident heat flux distribution over the sample surface for two cases.

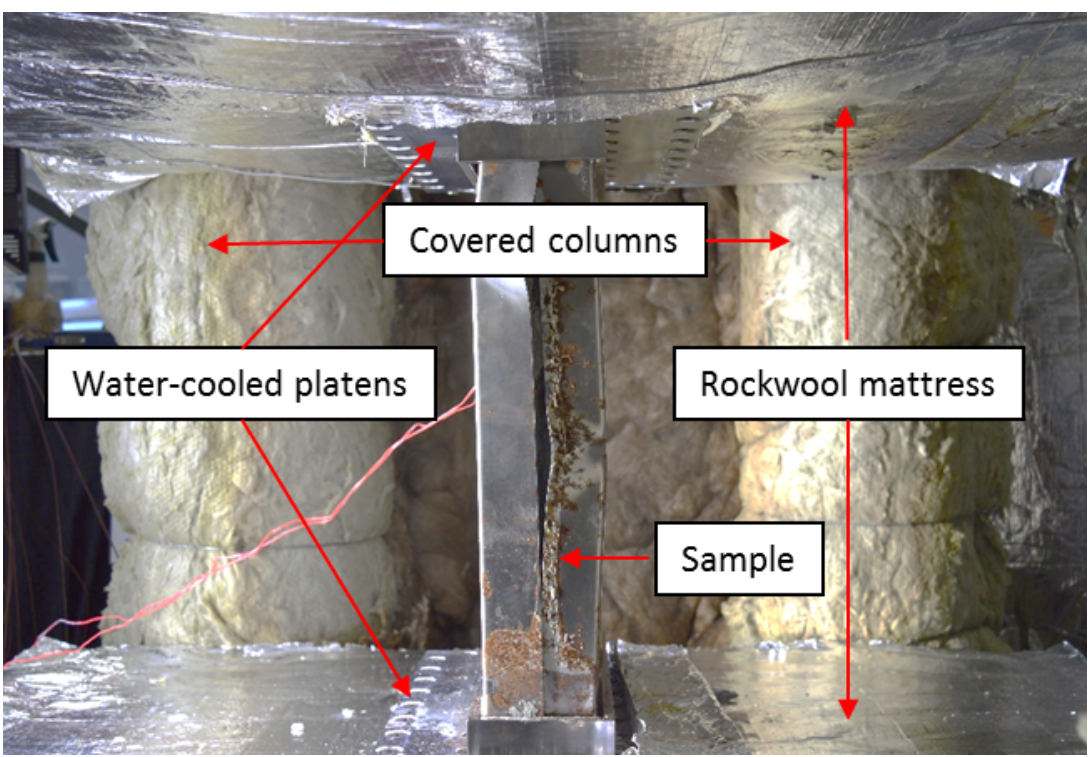

Fig. 8. Key details of the thermal insulation system to protect the MTS.
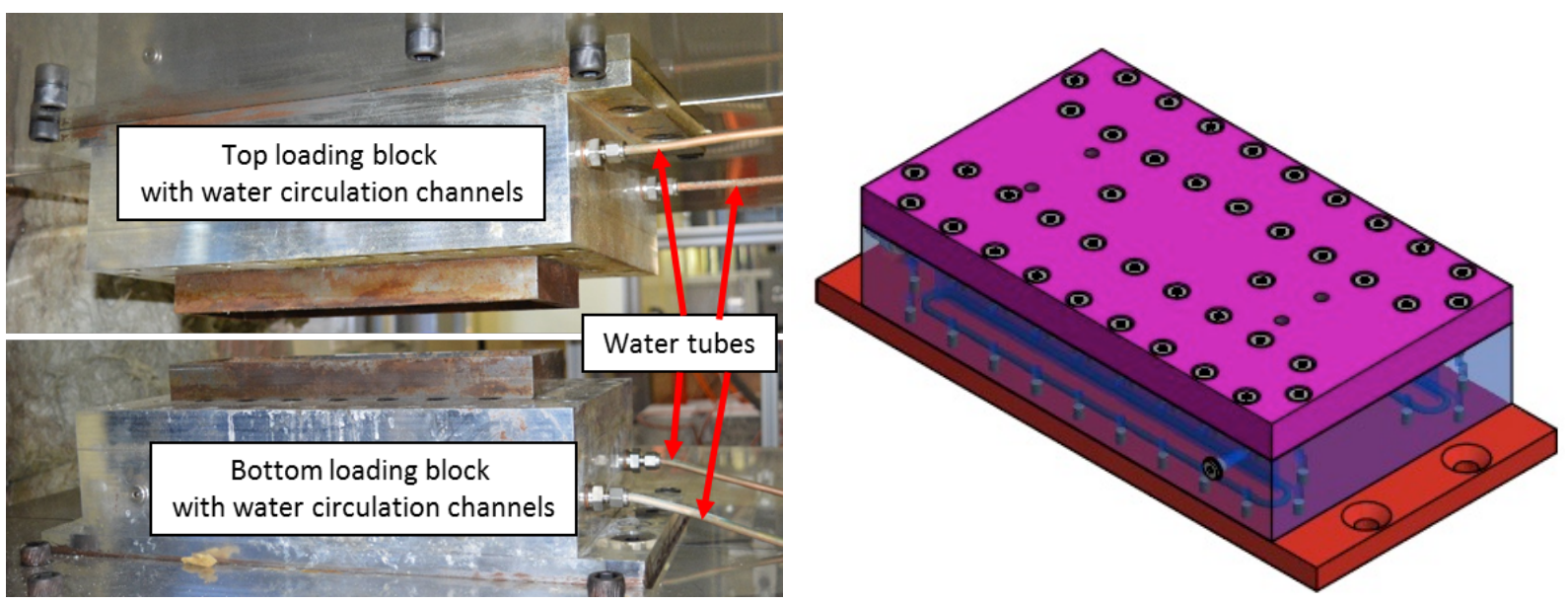

Fig. 9. Water-cooled system attached to the top and bottom surfaces of the samples. 
To achieve such insulation, two stainless steel sheets were attached to the heads of the actuator to block the convective heat from the burners (Fig. 8). Two Rockwool mattresses with a thickness of $50 \mathrm{~mm}$ were also tied to the stainless-steel sheets to enhance their insulation capacity. Additional plasterboard was then attached to the bottom surface of the top stainless-steel sheet to enhance the insulation capacity. Also, the Dynabreeze $750 \mathrm{~mm}$ Industrial Pedestal Fan was used to blow away the hot air on top of the actuator and thereby ensure the hydraulic lines remain cool. Care was taken to adjust the fan direction to minimise the possible effects of the fan on the convective heat loss from the surface of the sample. The MTS columns were covered by Rockwool mattresses with a thickness of $50 \mathrm{~mm}$. Trial tests were then performed, which proved the effectiveness of the above arrangement for thermal insulation.

In addition, a water-cooled system (Fig. 9) was placed at the top and bottom of the samples to minimise the heat transferred to the loading system. Aluminium was used to fabricate the water-cooled loading platens. The water channels were fabricated outside the loading zone to ensure uniform load transfer from the actuator to the samples. The water flow rate was controlled to ensure that the temperature of the loading heads remained below $30^{\circ} \mathrm{C}$ and no water dripping from the load platens to the samples.

\subsection{Test procedure}

The experiment was conducted in two stages: (i) heating stage, and (ii) loading stage; as detailed in the following.

\subsubsection{The heating stage}

Series 1 and 2 samples were subjected to the same heating stage. Series 1 samples were used to characterise the temperature profiles and gap size increase during the heating stage. Series 2 samples were first subjected to different structural boundary conditions before the start of heating. After being heated by 90 minutes, Series 2 samples were subjected to the loading stage. Series 2 samples were placed on the bottom disk, and then the top disk was moved down to contact the sample surface. The initial compression load was chosen as $0 \%, 20 \%$ or $40 \%$ of the axial load capacity of PCW at ambient temperature. The axial displacement of the actuator was fixed before and during the heating stage. The distance between the sample's heated surface and the radiant panel was set at $31.0 \mathrm{~cm}$ for the heat flux of $42 \mathrm{~kW} / \mathrm{m}^{2}$ and $24.7 \mathrm{~cm}$ for the heat flux of 60 $\mathrm{kW} / \mathrm{m}^{2}$, as detailed in Section 2.2.3.

As the radiant panels require about 3 minutes to reach their stable thermal condition, test samples were covered by a foil-faced Rockwool shield during this period to ensure they were subject to the target incident heat flux level during heating.

\subsubsection{The loading stage}

A loading rate of $1 \mathrm{~mm} / \mathrm{min}$ was chosen for all samples, both at ambient and high temperatures. After 90 minutes of heating, the radiant panels were turned off and moved away from the samples. The compressive loading was then applied within two minutes after turning off the radiant panels to minimise possible heat losses. If spalling occurred during the heating stage, the radiant burners were immediately turned off, and the loading was then applied.

\subsection{Testing conditions}

Two types of tests are conducted, and therefore the samples are split into two groups labelled as Series 1 and Series 2. The details of each series are provided as follows:

- Series 1 has four samples, used to characterise the temperature profiles on the cross-section of the samples and the steel sheets. Furthermore, the evolution of the gap formed between the concrete and the steel was captured in this series. Details of the thermocouples and methodology used to characterise the gap size are provided in Section 2.4.1.

- Series 2 has 15 samples, used to investigate the structural performance of PCW's under different thermal and structural boundary conditions. None of the samples had thermocouples. 


\subsubsection{Thermal characterisation}

224

Fig. 10 shows the thermocouple positions in Series 1 samples. Seven thermocouples located at seven depth levels were used to determine the internal temperature profiles on the cross-sections of the samples. The thermocouples (named TC1 through to TC7, respectively) were located at the interface between in-filled concrete and the heated steel sheet (TC1), at $10 \mathrm{~mm}$ (TC2), $20 \mathrm{~mm}$ (TC3), $30 \mathrm{~mm}$ (TC4), $40 \mathrm{~mm}$ (TC5), $60 \mathrm{~mm}$ (TC6) and on the backside of the unheated steel sheet (TC7). The distance between the adjacent wire thermocouples was $30 \mathrm{~mm}$. Additional thermocouple (TS) was attached on the surface of the heated steel sheet before the start of heating. This thermocouple was covered by aluminium foil to reduce the radiation heat from radiant panels, while maintained the physical contact with steel sheet to measure the temperature evolution of the heated steel sheet correctly (Fig. 17).

Three thick thermocouples (LVDT1, LVDT2 and LVDT3) were designed to simultaneously record the gap size increase between the heated steel sheet and concrete surface and the temperature of the heated steel sheet. To ensure their sufficient rigidity, thick thermocouples were used. Details of these thermocouples, together with the schematic of the system using these thermocouples for simultaneous measurement of the gap size and temperature of the heated steel sheet, are shown in Figs. 11 and 12. The objective is to ensure the tip of the three thick thermocouples in continuous contact with the surface of the heated steel sheet during the entire heating procedure. To achieve such continuous contact, three steel springs were used for each thick thermocouple. The length and stiffness of the steel springs were chosen to ensure insignificant compressive forces by the thermocouples on the heated steel surfaces. The tail ends of the thick thermocouples were attached to three LVDTs to capture the horizontal displacements, which allowed to examine the gap size increase during the heating procedure. The displacement results are discussed in Section 3.

In order to place thermocouples LVDT1, LVDT2 and LVDT3 in the correct positions, three TC's channels (5 mm diameter) were created by installing plastic rods into the samples before casting. The plastic rods were lubricated by WD- 40 to minimise the bonding between concrete and plastic rods. The plastic rods were then removed from the samples 3 hours after casting. The three channels constructed for the thick thermocouples exchanged heat with the concrete; nevertheless, they were believed to have an insignificant effect on the temperature distribution of the samples. During the heating stage, these TC's channels ( $5 \mathrm{~mm}$ diameter) were filled by the thick thermocouples ( $4.5 \mathrm{~mm}$ diameter). Thus, the actual gap of the channel was relatively small and thus providing a thermal barrier to the concrete. Therefore, the amount of heat, water and vapour escaping through the channels was deemed as negligible. Hence, the temperature increase in Series 1 samples was representative of the temperature increase in Series 2 samples.

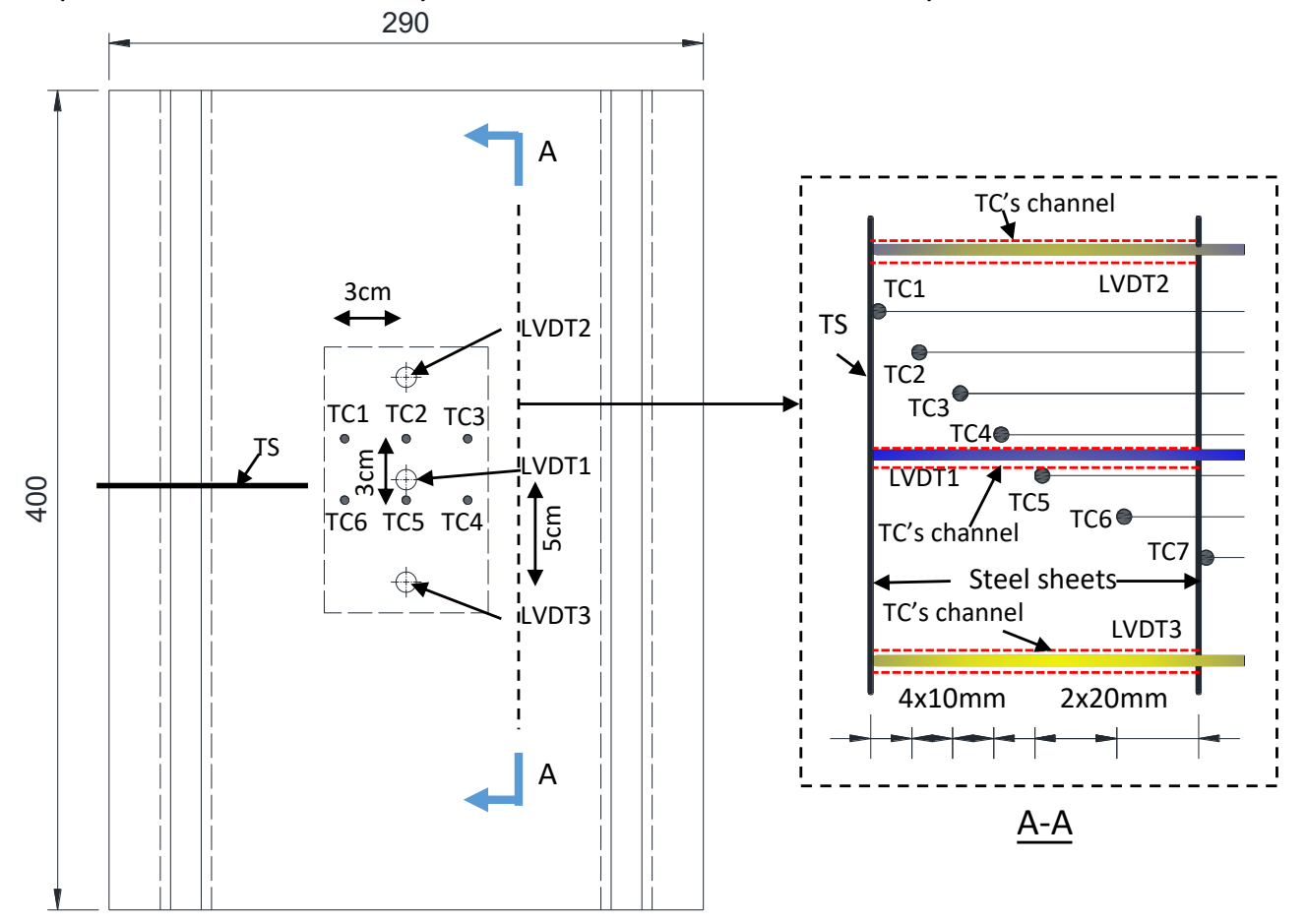

Fig. 10. Thermocouples' positions in Series 1. 


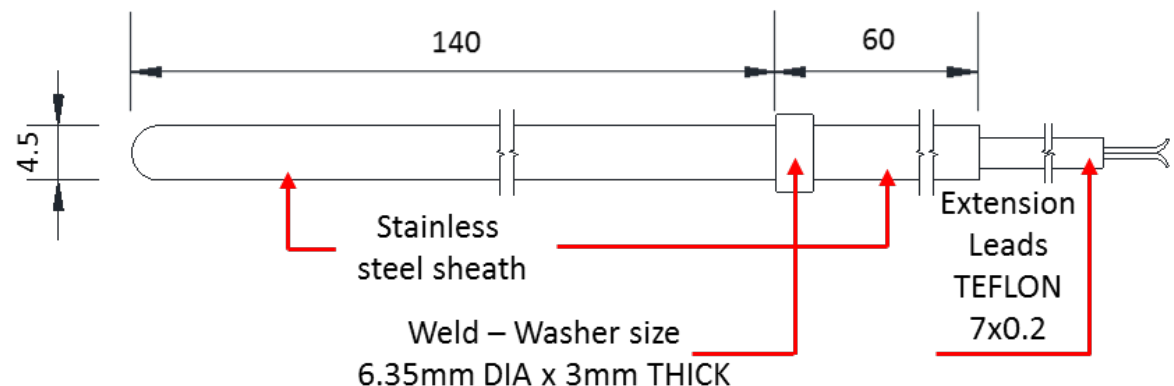

Fig. 11. Thick thermocouples for simultaneous measurement of the gap size and temperature of the heated steel sheet.

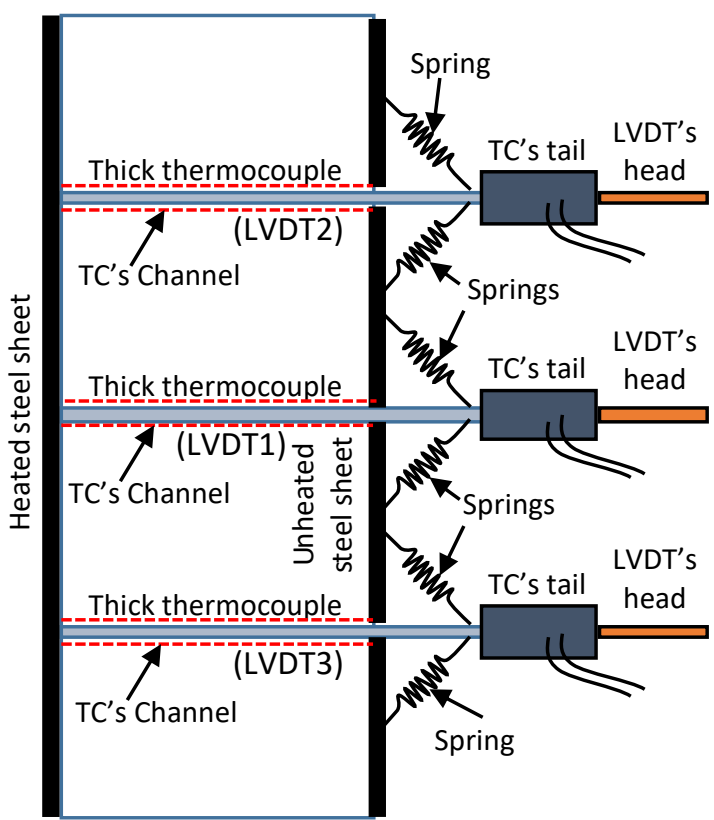

Fig. 12. Schematic of the system for simultaneous measurement of the gap size and temperature of the heated steel sheet.

\subsubsection{Mechanical testing}

Table 1 summarises the testing conditions for all 19 samples in this study. The following tests were conducted:

- Series 1 samples (Tests 1-1 to 1-4) were heated for 90 minutes at two incident heat fluxes $\left(42 \mathrm{~kW} / \mathrm{m}^{2}\right.$ and $60 \mathrm{~kW} / \mathrm{m}^{2}$ ). There were two samples for each incident heat flux and the temperature evolution and gap size between the steel sheet and concrete surface with time were recorded.

- Test 2-1 and Test 2-2 samples were axially loaded until failure at ambient temperature. These tests allow to evaluate the axial load capacity $\left(N_{u}{ }^{a m b}\right)$ and load-deformation diagram for the PCWs at ambient temperature.

- Test 2-3 and Test 2-4 were uniaxially compressed until failure at ambient temperature with loading at an initial eccentricity of $10 \mathrm{~mm}$ from the neutral axis. The data collected from this test is used to assess the effect of eccentricity on the axial load capacity of PCWs at ambient temperature.

- For Tests 2-5 through to 2-15: During heating, the axial displacement was kept unchanged while the thermal reaction force was recorded. The test was stopped either after 90-min of heating or after the occurrence of explosive spalling in the concrete core, whichever occurred first.

- Four tests were heated with top and bottom end surfaces fixed but with no initial compressive load. Two samples were subject to HF42 (Tests 2-5 and 2-6) and the other two to HF60 (Tests 2-11 and 2-12).

- Two samples (Tests 2-7 and 2-8) were subjected to $0.4 N_{u}^{a m b}$ with no eccentricity before heating. The samples were then subjected to HF42. 
- Two samples (Tests 2-9 and 2-10) were subjected to a $0.2 \mathrm{~N}_{u}{ }^{\mathrm{amb}}$ load applied with a $10 \mathrm{~mm}$ eccentricity in the direction of the heating source. The load was applied before heating. The samples were then heated by HF42.

- Three samples (Tests 2-13 to 2-15) were subjected to a $0.2 N_{u}^{a m b}$ load applied with no eccentricity. The load was applied before heating. The samples were then heated by HF60.

Table 1. Test schemes.

\begin{tabular}{|c|c|c|c|c|c|}
\hline Series & Sample ID & $\begin{array}{l}\text { Initial } \\
\text { compressive } \\
\text { load } \\
\left(\% \text { of } \mathrm{N}_{\mathrm{u}}{ }^{\mathrm{amb}}\right)\end{array}$ & $\begin{array}{l}\text { Initial } \\
\text { eccentricity } \\
(\mathrm{mm})\end{array}$ & $\begin{array}{l}\text { Incident heat } \\
\text { flux at the } \\
\text { heated steel } \\
\text { surface } \\
\left(\mathrm{kW} / \mathrm{m}^{2}\right)\end{array}$ & $\begin{array}{l}\text { Number of } \\
\text { replicate } \\
\text { samples }\end{array}$ \\
\hline \multirow{2}{*}{ Series 1} & $\begin{array}{l}\text { Test } 1-1 \\
\text { Test } 1-2\end{array}$ & 0 & 0 & 42 & 2 \\
\hline & $\begin{array}{l}\text { Test } 1-3 \\
\text { Test 1-4 }\end{array}$ & 0 & 0 & 60 & 2 \\
\hline \multirow{10}{*}{ Series 2} & $\begin{array}{l}\text { Test 2-1 } \\
\text { Test 2-2 }\end{array}$ & 0 & 0 & 0 & 2 \\
\hline & $\begin{array}{l}\text { Test 2-3 } \\
\text { Test 2-4 }\end{array}$ & 0 & 10 & 0 & 2 \\
\hline & $\begin{array}{l}\text { Test 2-5 } \\
\text { Test 2-6 }\end{array}$ & 0 & 0 & 42 & 2 \\
\hline & $\begin{array}{l}\text { Test 2-7 } \\
\text { Test 2-8 }\end{array}$ & 40 & 0 & 42 & 2 \\
\hline & $\begin{array}{l}\text { Test 2-9 } \\
\text { Test 2-10 }\end{array}$ & 20 & 10 & 42 & 2 \\
\hline & $\begin{array}{l}\text { Test } 2-11 \\
\text { Test } 2-12\end{array}$ & 0 & 0 & 60 & 2 \\
\hline & Test 2-13 & & & & \\
\hline & Test 2-14 & 20 & 0 & 60 & 3 \\
\hline & Test 2-15 & & & & \\
\hline & Total samples & & & & 19 \\
\hline
\end{tabular}

\section{RESULTS OF THE THERMAL CHARACTERISATION: TEMPERATURE AND GAP SIZE INCREASE}

This section presents the thermal characterisation of the samples. Only Tests 1-1 to 1-4 are used for this purpose. It was assumed that the temperature profiles obtained from these tests were consistent with those of Series 2, as discussed earlier. To avoid any effect of the thermocouples on the mechanical behaviour of the samples, none of the samples of Series 2 included temperature measurements.

Figs. 13 and 14 show the time evolution of in-depth temperatures for specimens when heated by HF42 and HF60, respectively. As can be seen from these figures, the temperature of the steel sheets rapidly increases in the first 15 minutes for the case of HF42 and 10 minutes for HF60. At this point there is a noticeable change in the slope of the steel temperature (TS); thereafter, the temperature increases at a much slower rate from around $450^{\circ} \mathrm{C}$ to $550^{\circ} \mathrm{C}$ within 75 minutes (HF42) and from around $500^{\circ} \mathrm{C}$ to $680^{\circ} \mathrm{C}$ within 80 minutes (HF60). At the transition point, the steel temperature (TS) shows that heat transfer through the steel to the concrete also changes. The thermocouple readings also show a change in slope, but in the case of the concrete surface (TC1), the rate of change in temperature increases.

The thermal conductivity of concrete $(\sim 1.8 \mathrm{~W} / \mathrm{mK})$ and that of steel $(\sim 40 \mathrm{~W} / \mathrm{mK})$ are significantly different, resulting in a discontinuity in the in-depth temperature gradient at the interface between both materials. Nevertheless, if both materials act as a composite, the discontinuity does not manifest itself in the temperature histories. In contrast, the formation of small air gaps creates a region of low thermal 
steel (TS). Fig. 15 shows that the temperature difference (TS - TC1) between the steel plate changes in time. Given that the two thermocouples are separated, there was always a difference in temperature. If the heat flux is assumed constant, then the more extensive the temperature difference, the lower the effective thermal conductivity of the material between the thermocouples. If the concrete is adhered to the steel, only the steel plate separates the two thermocouples. Because of the high thermal conductivity of the steel, at the onset of heating, the difference is very small. As observed in Fig. $\mathbf{1 5}$ the temperature difference starts increasing until it reaches a maximum. The increase in temperature could be linked to a decrease in the effective thermal conductivity associated with the formation of a small gap. The small gap was filled with stagnant air and given that air has a very low thermal conductivity $(\sim 0.02 \mathrm{~W} / \mathrm{mK})$, the temperature difference increased significantly. As the deformations continue to increase and the gap gets larger and a critical length scale that defines the onset of buoyancy-driven convection is attained. Convection is a much more effective mode of heat transfer resulting in a decrease in the temperature difference. After 1.5 hours of heating, the temperature difference between the steel sheet and concrete surface disappears in the case of an incident heat flux of $42 \mathrm{~kW} / \mathrm{m}^{2}$. In the case of $60 \mathrm{~kW} / \mathrm{m}^{2}$, the temperature difference between the steel sheet and the concrete surface remains around $50^{\circ} \mathrm{C}$.

In this test, the three thick thermocouples and springs system were used to capture the increase of the gap size between the heated steel sheet and concrete core surface. The temperatures recorded in these thick thermocouples are, however, not reported in this paper because of their poor qualities due to the thermocouples' direct exposure to the moisture escape through the prefabricated channels. The gap size increase collected from this test is plotted in Fig. 16. It is apparent from this figure that the magnitude of the gap as recorded by LVDT1, LVDT2, and LVDT3 needs to be carefully analysed. For HF60, the gap size measured by LVDT2 increased up to $6.5 \mathrm{~mm}$ while the gap size of LVDT1 increased only to $2 \mathrm{~mm}$. The gap size at LVDT2 seemed to increase rapidly since the beginning of the heating stage, then stabilized at its maximum value of around $6.5 \mathrm{~mm}$ while the gap measured by LVDT3 was consistent with that by LVDT1 throughout the heating process. Similar behaviour was observed for HF42 but with a gap dimension never exceeding $2 \mathrm{~mm}$. The gap measured by LVDT2 increased first while LVDT1 and LVDT3 measured an increase of the gap to a similar magnitude at $35 \mathrm{~min}$ and $60 \mathrm{~min}$, respectively. It should be noted that the lateral deformation of the heated steel sheet surface was visually observed to be non-uniform and evolve with time; and, by inference, so was the gap size between the heated steel sheet surface and concrete core (Fig. 17).

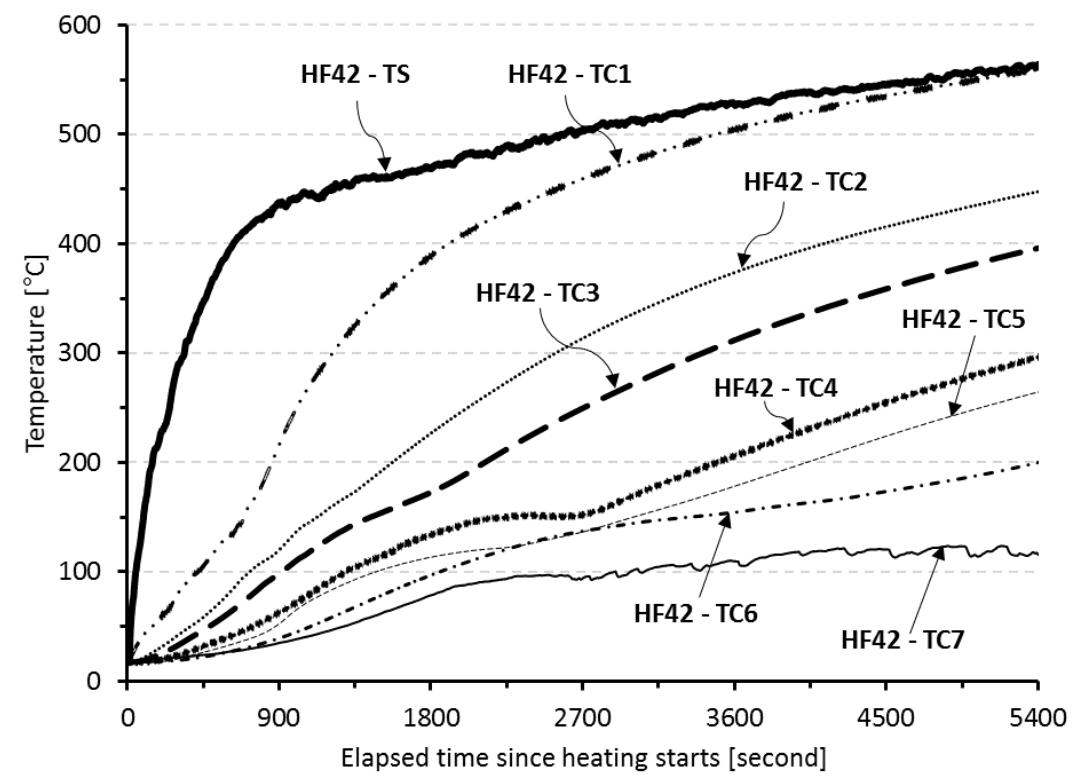

Fig. 13. Temperature development at eight positions of thermocouples in the samples heated by HF42 (Test 1-1).

Gap magnitude measurements, in-depth temperature measurements and visual observations are all consistent in describing the effects generated by the separation of the steel from the concrete. While these observations should be treated as qualitative, they provide a clear phenomenological explanation of the effect of heat on the interaction between the concrete and the steel. 


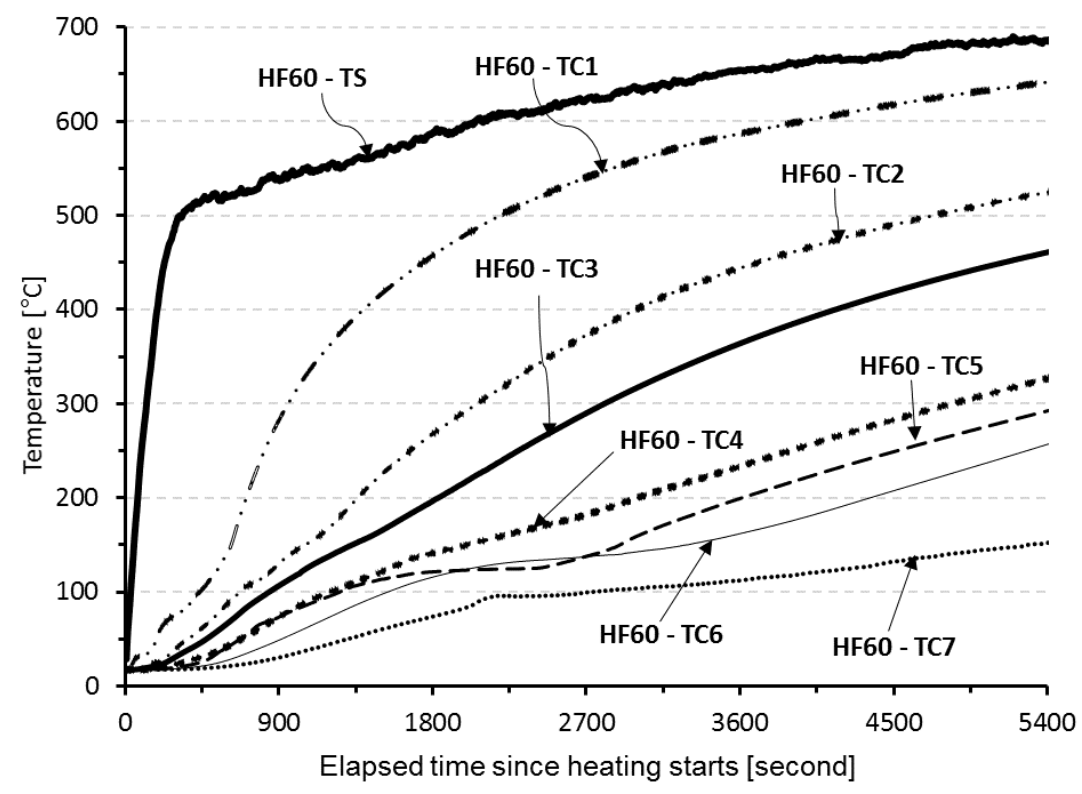

Fig. 14. Temperature development at eight positions of thermocouples in the samples heated by HF60 (Test 1-3).

As heat is transferred in-depth in the concrete core, each location in the concrete the temperature reaches a water evaporation plateau at around $100-150^{\circ} \mathrm{C}$ (Figs. 13 and 14). Previous studies have identified this plateau for other experimental set-ups [30] and with the current set-up by Le et al. [27]. The plateau becomes more evident deeper in the sample because of the migration and condensation of moisture toward the colder region in the heated sample. The range of $110^{\circ} \mathrm{C}$ and $200^{\circ} \mathrm{C}$ seems to be consistently quoted as the critical temperature of physically and chemically bound water inside concrete [30]. The absorbed energy firstly serves to evaporate the accumulated pore water, after which the concrete temperature increases again. Thus, the temperature closer to the heated surface (where the supply of heat is greater) stays for a shorter time on its plateau. Also, the temperature plateau on the back surface of the samples dropped to around $100^{\circ} \mathrm{C}$ because of the accumulation of re-condensed water vapour. In Series 1 tests, a significant amount of vapour was observed through the three prefabricated channels of thick thermocouples, while an insignificant amount of water accumulation was observed on the top and bottom faces of the sample. In Series 2, the moisture evaporation from the samples cannot be observed clearly because these samples have no channels for thermocouples, but given that similar water migration/bleeding can be clearly observed on the top and bottom surfaces of samples, the behaviour of the samples is assumed similar.

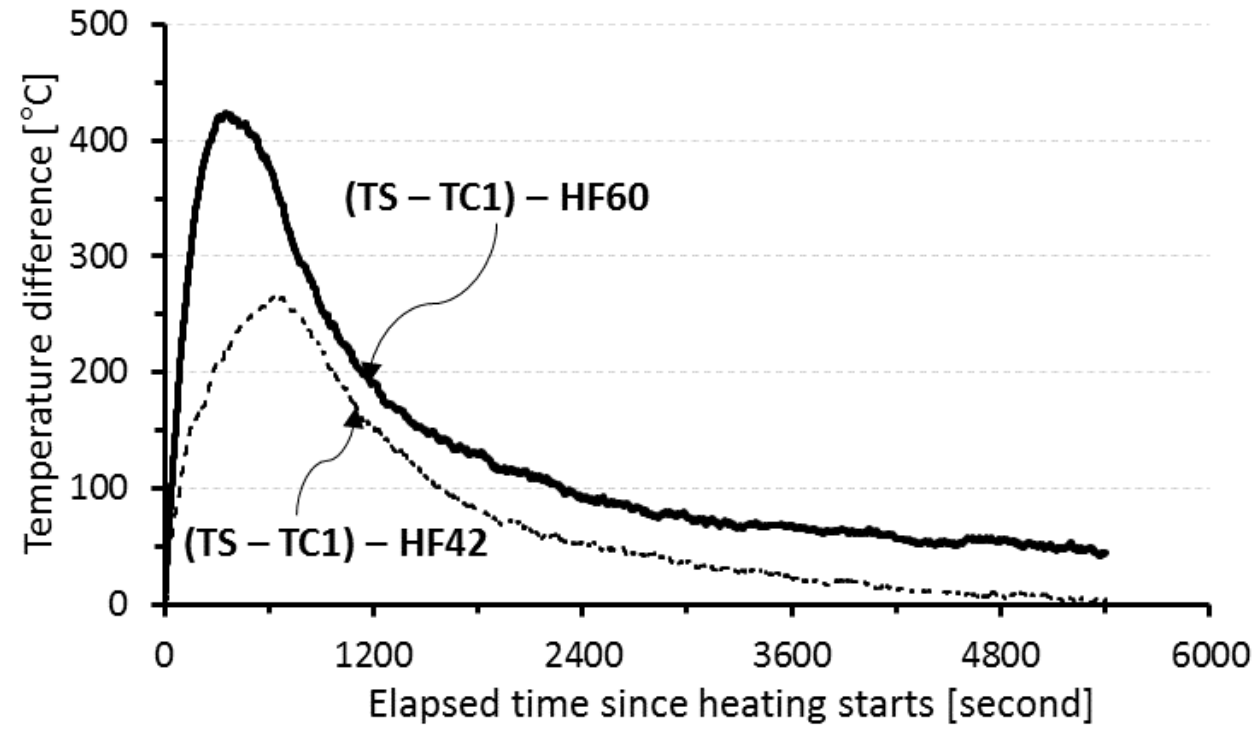

Fig. 15. The temperature difference between heated steel sheeting and concrete surface in samples heated by HF42 and HF60. 


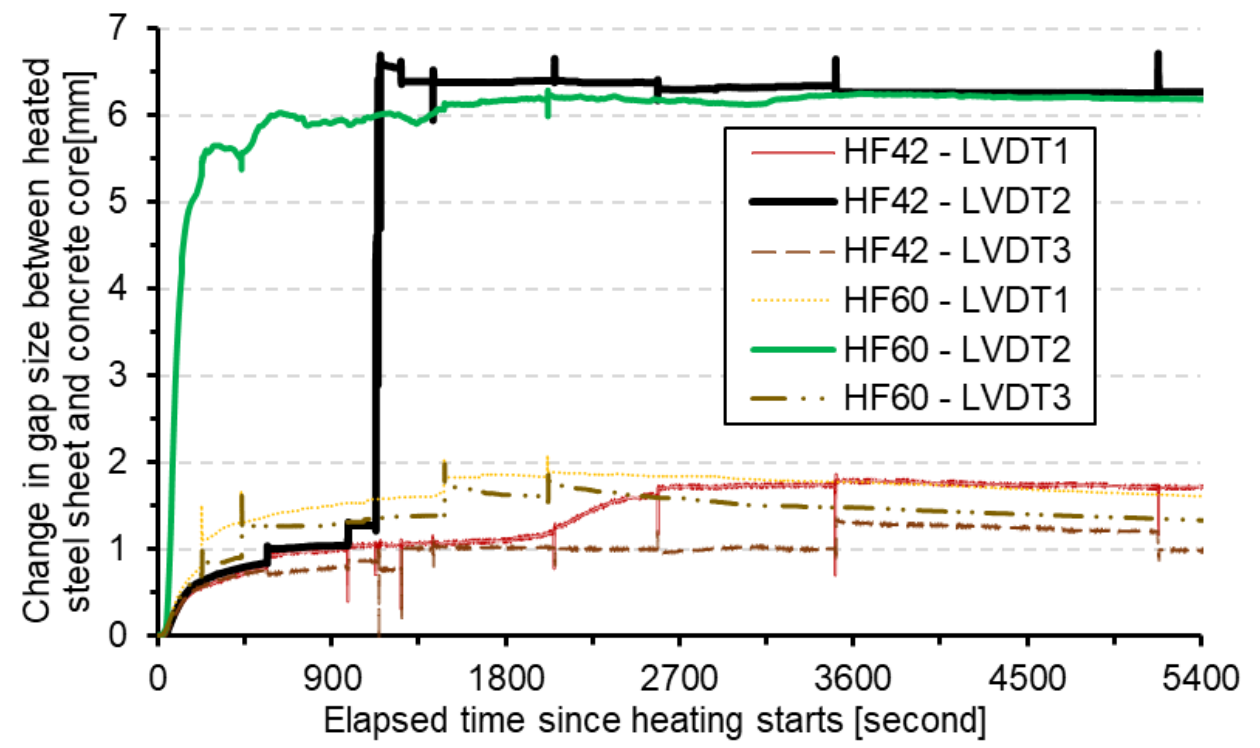

Fig. 16. Gap increase captured from the samples Series 1 heated by HF42 and HF60.
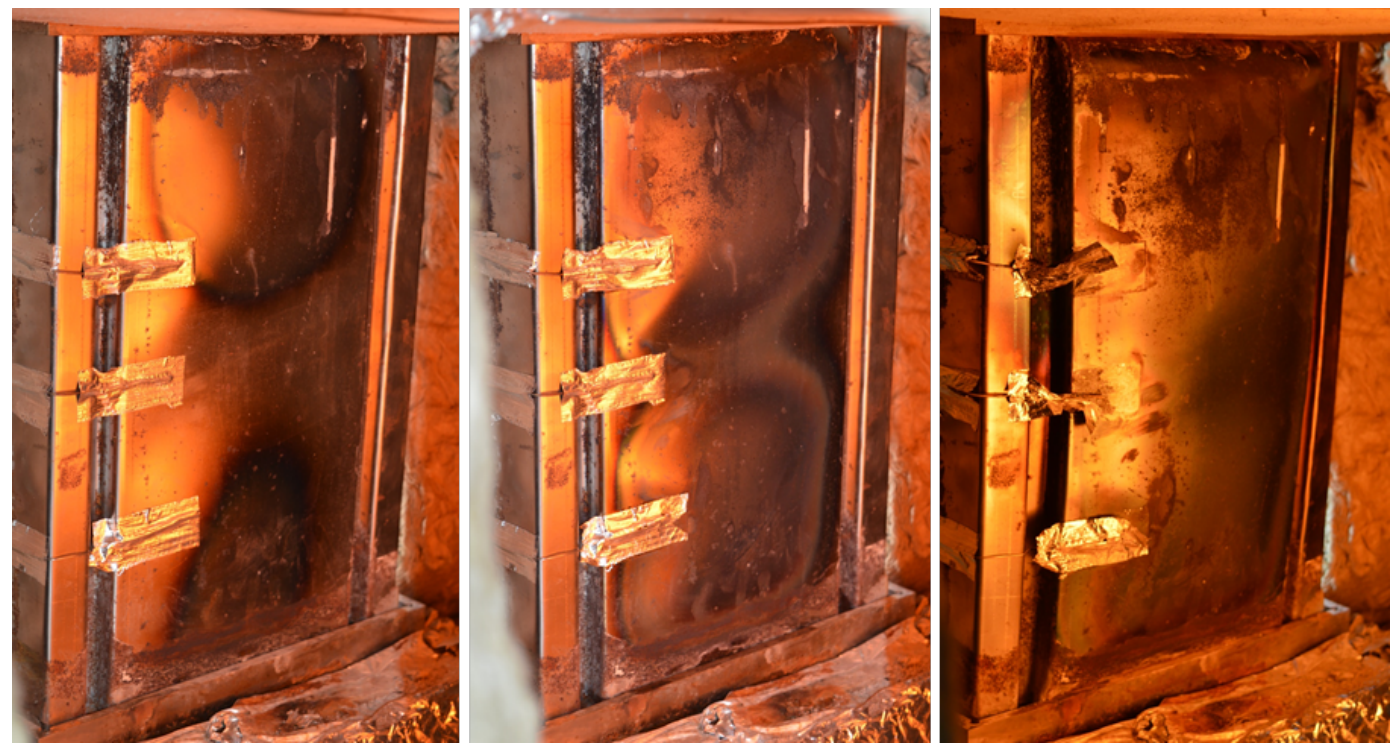

Fig. 17. Typical deformation of the steel sheet on the heated side: (a) during the initial period of heating; (b) during the later stage of heating; and (c) in cases of spalling of in-filled concrete.

Fig. 18 shows the temperature profiles in the samples at different heating times (15, 30, 60 and 90 minutes). Given that the tests with HF60 are receiving more heat flux than those exposed to HF42, it is expected that the gradient at the surface is greater in the higher the heat flux. Indeed, as shown in Fig. 18, that is only the case for the first $15 \mathrm{~min}$ of heating when there is adhesion between steel plate and concrete. This evolves once this initial period has past and while the concrete absorbs more heat, the higher the heat flux, the difference between the gradients diminishes with time. While it is not clear what the gradients are very close to the surface, and it is likely that they are higher for higher heat fluxes, the prior statements apply to the greater part of the cross-section. The resolution is given by the position of the thermocouples, and it is very difficult to place several thermocouples very close to each other. The water evaporation (re-condensation) front most likely also has an effect on the in-depth temperature distribution. After 90 minutes, the samples heated by $\mathrm{HF} 60$ have attained an average temperature of $342^{\circ} \mathrm{C}$ as compared to the average temperature in samples heated by $\mathrm{HF} 42$ of $291^{\circ} \mathrm{C}$. However, the temperature gradient within the samples' cross-section heated by HF42 and HF60 remain almost identical. 


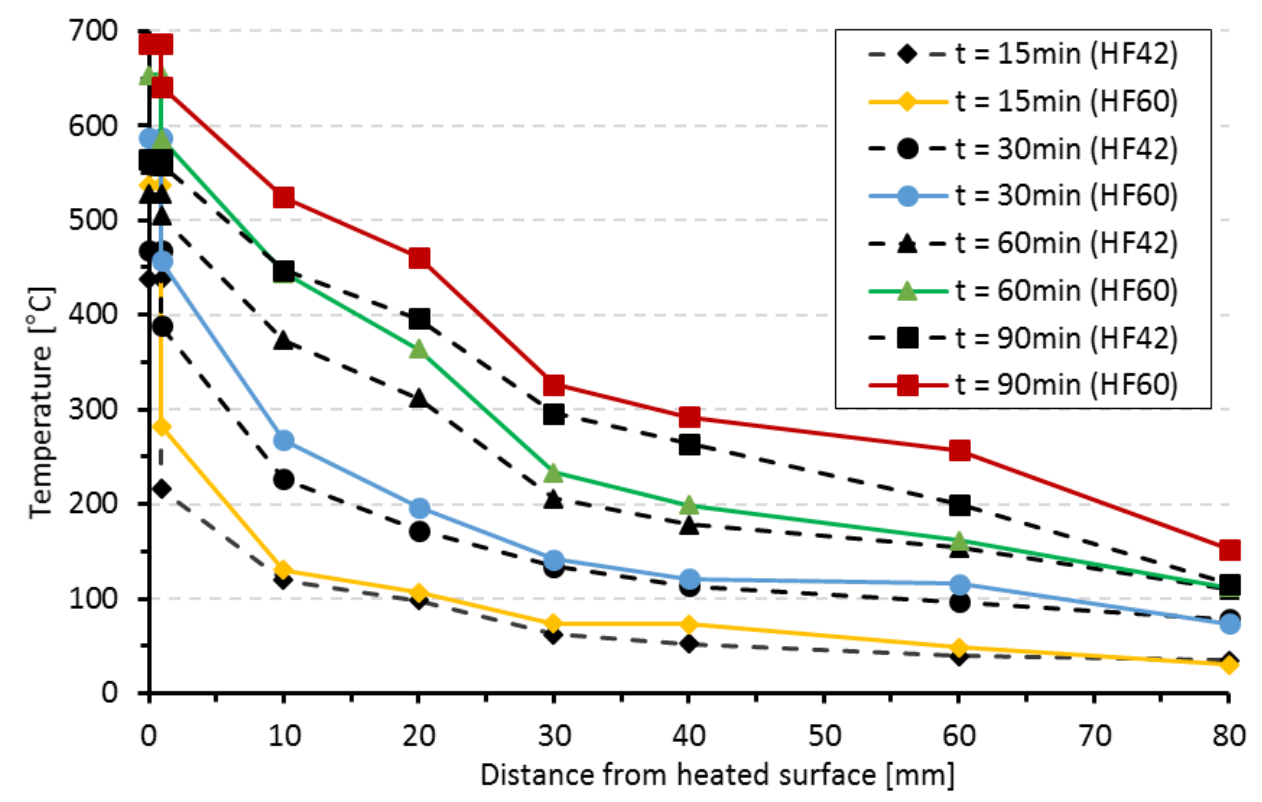

Fig. 18. Temperature profiles of the samples heated by HF42 and HF60 at 15, 30, 60, and 90 minutes.

\section{THE TEST RESULTS AT AMBIENT TEMPERATURE}

This section describes the test results at ambient temperature. Four samples were displacement-controlled loaded at the rate of $1 \mathrm{~mm} / \mathrm{min}$ until failure: two samples with zero initial eccentricity (Tests 2-1 and 2-2) and the other two with an initial eccentricity of $10 \mathrm{~mm}$ (Tests 2-3 and 2-4). The purpose of these tests was to establish the baseline behaviour of the cold PCWs.

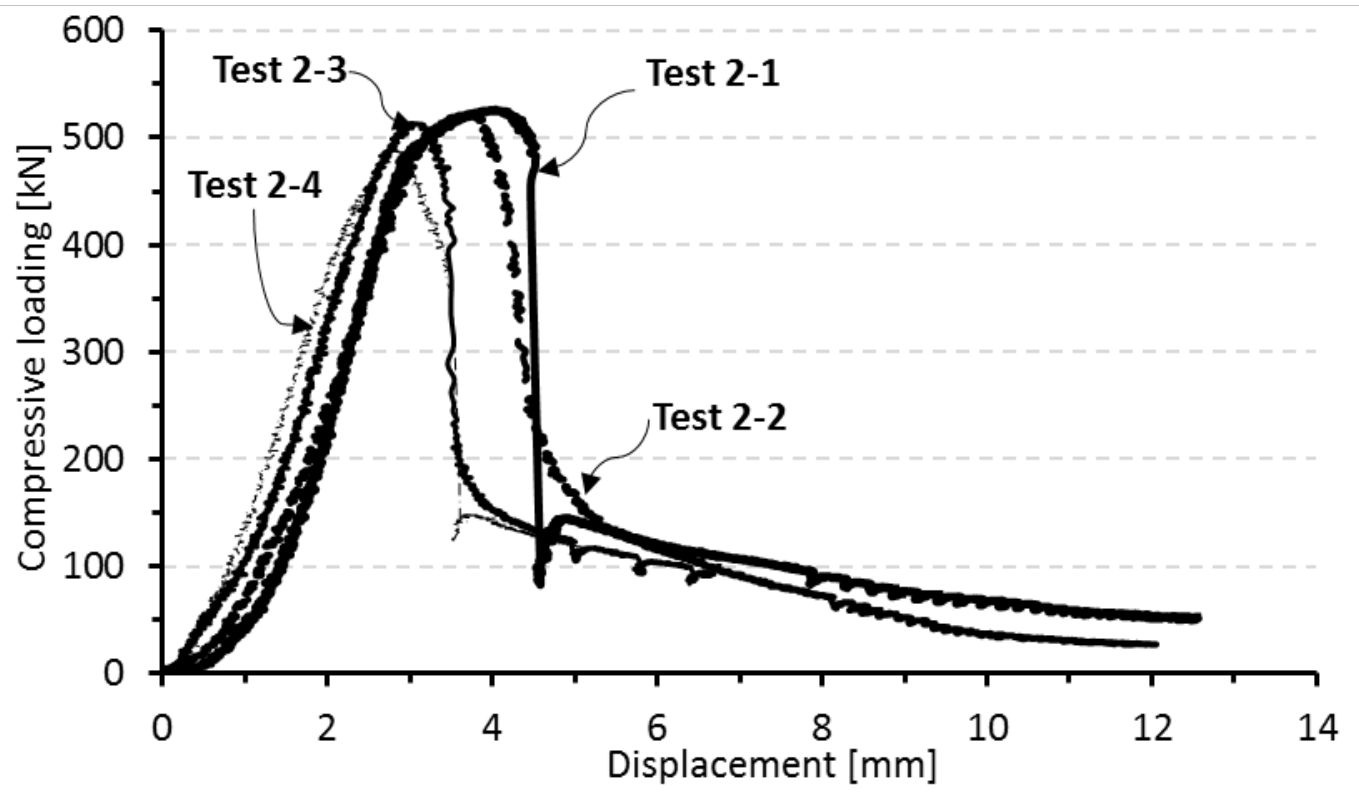

Fig. 19. Load-axial displacement behaviour of Series 2 samples under compressive loading at ambient temperature.

The results from Tests 2-1 to 2-4 give confidence to the reliability of the overall experimental program because of the high consistency of the axial load capacity of samples tested under the same loading conditions. Once the compressive load was increased in samples through the displacement controlled of the actuator, the load-displacement behaviour of the samples followed the curve shown in Fig. 19. The difference of the axial load capacity was negligible $(527 \mathrm{kN}$ and $524 \mathrm{kN})$ in samples tested in concentric loading condition. When the samples were loaded with an eccentricity of $10 \mathrm{~mm}$, the load capacity was less than $5 \%$ difference of $513 \mathrm{kN}$ (Test 2-3) and $492 \mathrm{kN}$ (Test 2-4), respectively. In the cases with an initial eccentric load, an unsymmetrical failure of the steel sheets and concrete core was observed. For the samples loaded eccentrically, the displacement at the ultimate load was approximately $2.8 \mathrm{~mm}$ while for the axially loaded samples, it was approximately $3.3 \mathrm{~mm}$. These minor differences could be linked to the non-uniform 
distribution of compressive stress generated by the eccentricity on the cross-section of the samples. After reaching the ultimate load capacity, the compressive load in the samples significantly dropped to around 150 $\mathrm{kN}$, then gradually decreased when the displacement was further increased.

Figs. 20 and 21 show the failure modes at ambient temperature when the samples were subject to axial loadings at either 'zero initial eccentricity' or ' $10 \mathrm{~mm}$ initial eccentricity'. For the zero initial eccentricity loaded samples, buckling of the steel sheets was symmetrical. Fig. 20 shows the buckling occurred simultaneously and at almost the same height on both sides of the sample when the load was applied axially. Shortly after the buckling of steel sheets on both sides, the crushing of the concrete core occurred. When the samples were eccentrically loaded, failure was unsymmetrical (Fig. 21). The steel sheet in the high compressive stress region exhibited the local buckling earlier followed by the crushing of the concrete, while the steel sheet on the other side remained undeformed during the heating stage. Importantly, all samples experienced a ductile failure, as evidenced by the long post-break plateau in the load-displacement response (Fig. 19). As discussed in Section 1, such ductile failure is among the significant advantages of PCWs.

It should be noted that the steel sheet does not provide an improvement due to confinement. The samples do not have intermediate fasteners embedded; therefore, the bond between the steel sheet and concrete surface is weak and subsequently, the effect of confinement on the load capacity of the PCW is small.
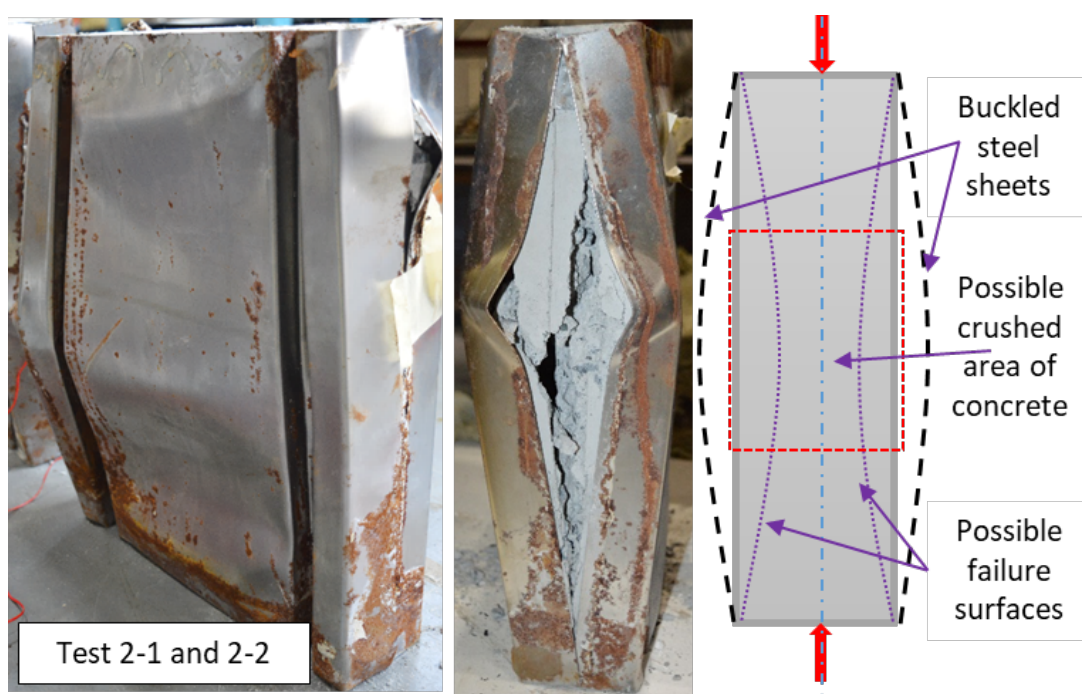

Fig. 20. Failures of Series 2 samples subjected to 'zero initial eccentricity' at ambient temperature.

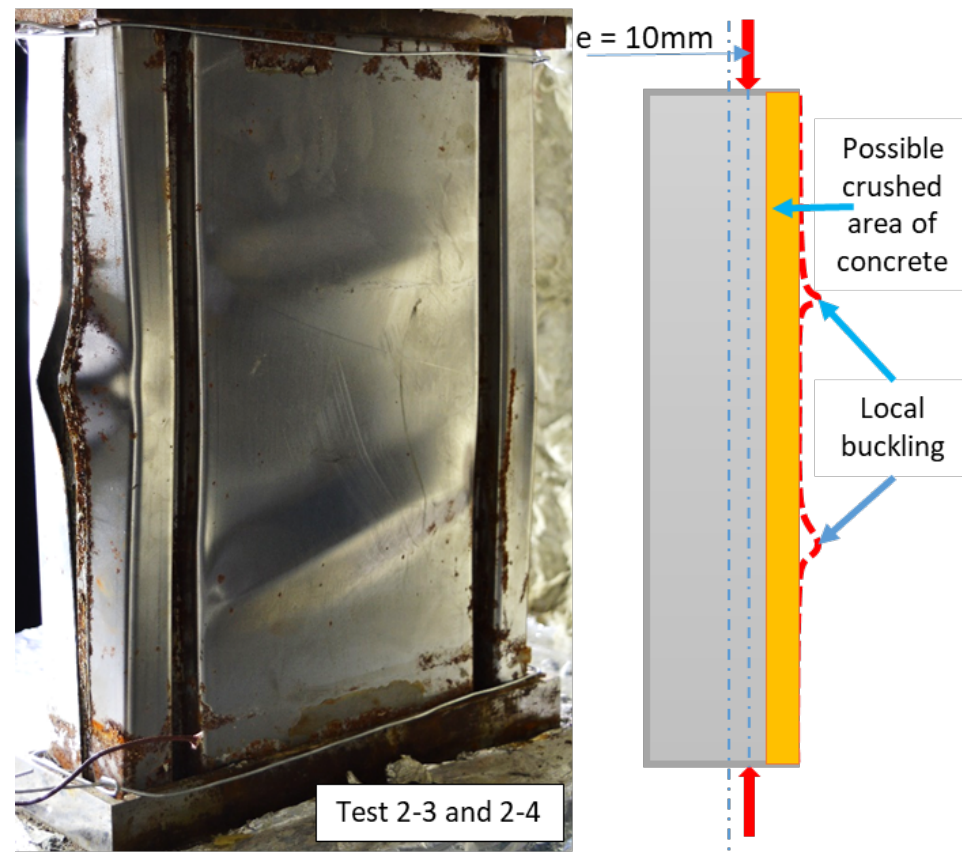

Fig. 21. Failures of Series 2 samples subjected to $10 \mathrm{~mm}$ initial eccentricity of load at ambient temperature. 


\section{TEST RESULTS FROM THE HEATED EXPERIMENTS}

\subsection{During the heating stage}

As explained in the previous sections, heating of the sample led to an increase in temperature and the formation of thermal gradients. The temperature increase resulted in thermal expansion while the gradients induced curvature and eccentricity. Fig. 22 shows the evolution of the compressive forces of samples heated by HF42 and HF60, where no initial compressive load was applied. As can be seen from the figure, heating results in a steady increase of the measured load in Tests 2-5 and 2-6. The figure presents two identical tests, one resulted in only minor spalling after approximately 60 minutes (Test 2-5) while for the other minor spalling occurred after $10 \mathrm{~min}$ and then major spalling after $65 \mathrm{~min}$ (Test 2-6). Spalling results in a sudden reduction of the load but further heating leads to a continuous increase of the load at a rate slightly more extensive than that of the non-spalling sample. This is very noticeable in the Tests 2-5 and 2-6 that if spalling is significant, while it is almost unnoticeable if spalling is minor. For both samples, spalling (minor and major) occurred consistently when the force induced by thermal expansion reached 50 to $60 \mathrm{kN}$. It is important to note that this is approximately $10 \%$ of the ambient load capacity of the samples. At the moment of explosive spalling, the steel sheet on the heated side was pushed toward the heating source due to the impact loading created by the concrete debris. After $90 \mathrm{~min}$ of heating time, the thermal expansion forces in these samples were around $55 \mathrm{kN}$ for the spalled sample and $70 \mathrm{kN}$ for the less spalled one.

Fig. 22 also presents the thermal expansion force for the two samples heated with HF60 (Test 2-11 and 212). The increase in load follows the same pattern as the samples heated with HF42 but, as expected, the load builds faster. Spalling once again occurred when the thermal expansion load reached approximately 50 $\mathrm{kN}$, but Test 2-12 seems to build up the load slightly faster (Table 2). As indicated in Table 2, spalling occurs approximately with a $5 \mathrm{~min}$ difference between the two repeats. The reason for this difference might be a slight variation in the gap formation that results in a different heat transfer rate from the steel to the concrete. Given that the samples do not have thermocouples, it is not possible to precisely ascertain what the differences are, nevertheless, the differences are minor, and so the two tests confirm the patterns of behaviour.

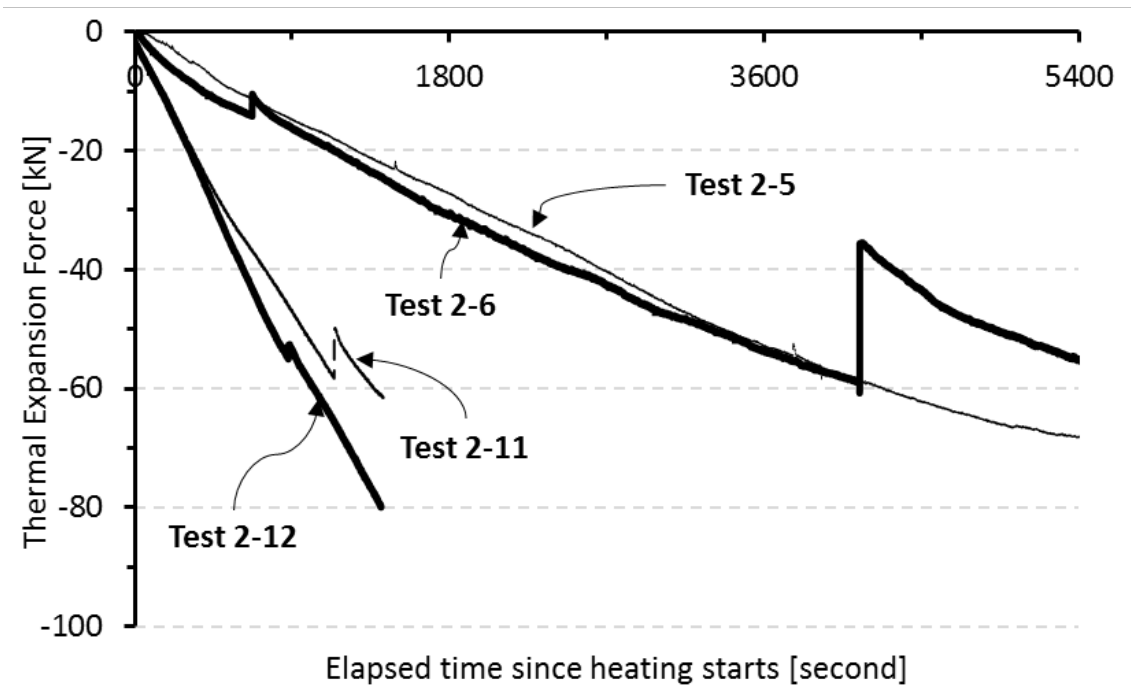

Fig. 22. Thermal expansion forces developed in samples heated by HF42 and HF6 and PO. 


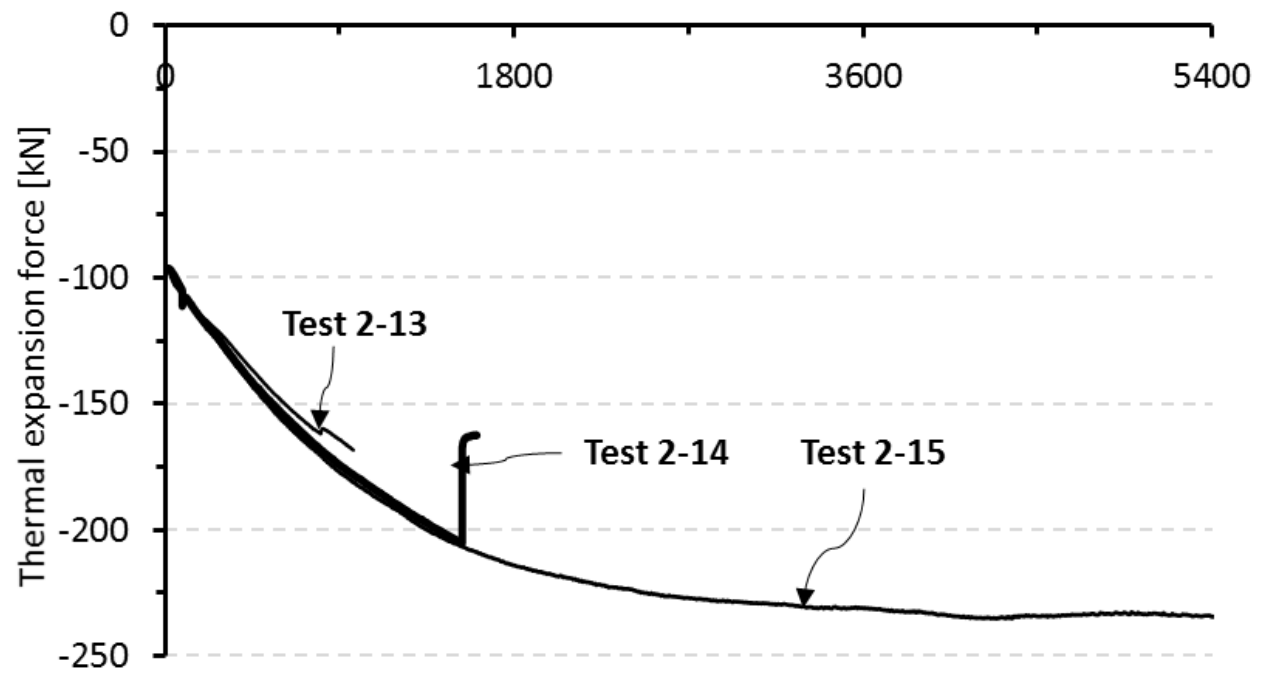

Elapsed time since heating starts [second]

a) Series 2 samples heated by HF60 and P2O.

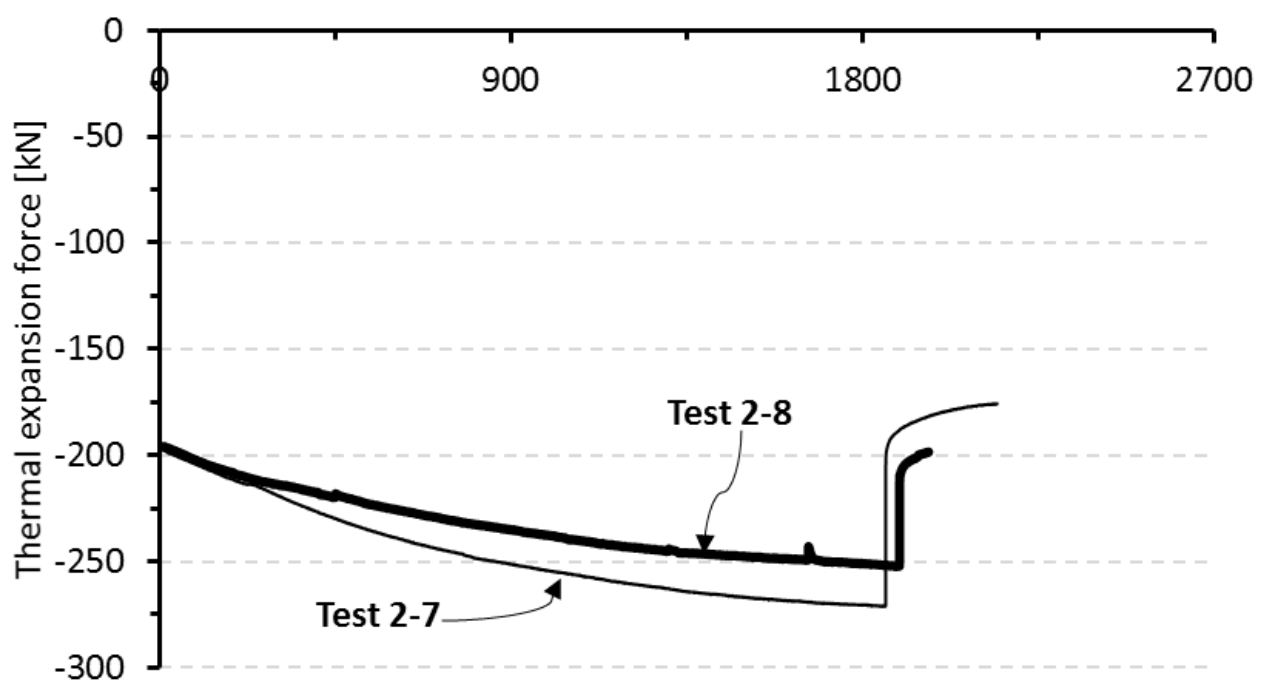

Elapsed time since heating starts [second]

b) Series 2 samples heated by HF42 and P4O.

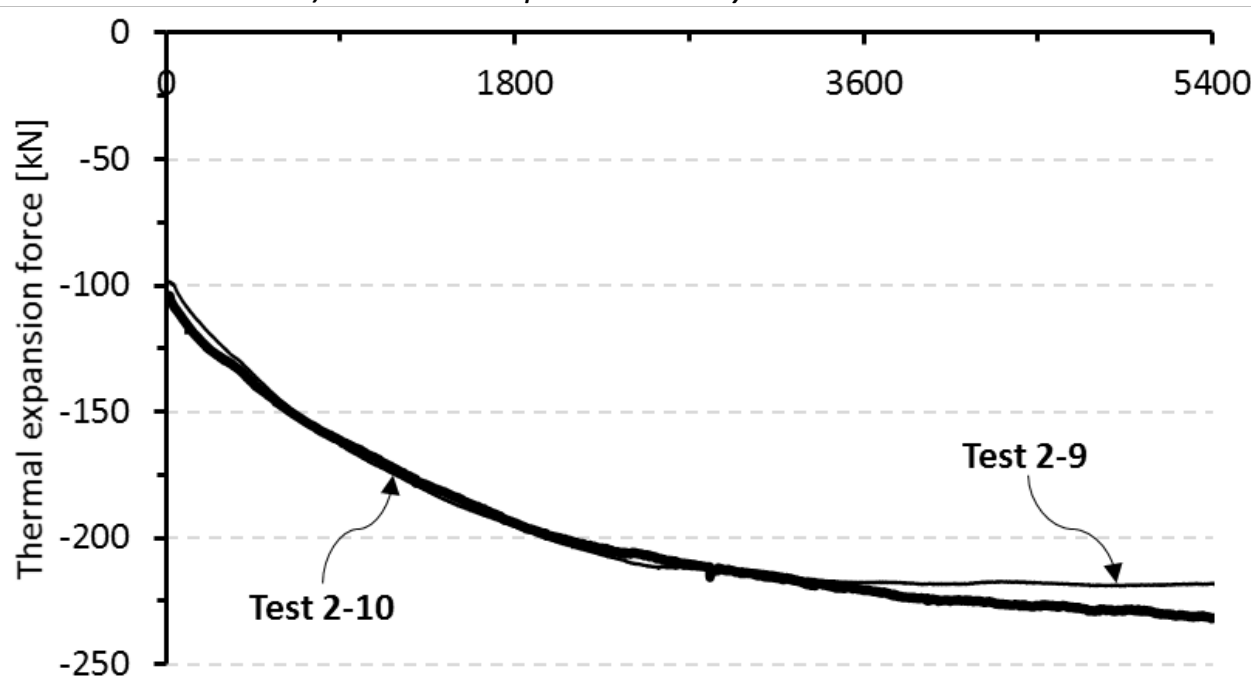

Elapsed time since heating starts [second]

c) Series 2 samples heated by HF42, P2O and E10. 
Table 2. Time of explosive spalling and thermal reaction forces.

\begin{tabular}{|c|c|c|c|c|c|}
\hline \multirow{2}{*}{ Sample ID } & \multirow{2}{*}{$\begin{array}{l}\text { Time of spalling } \\
\text { since start of } \\
\text { heating ( } \mathrm{min} \text { ) }\end{array}$} & \multicolumn{2}{|c|}{$\begin{array}{l}\text { Recorded maximum } \\
\text { compressive load (kN) }\end{array}$} & \multirow{2}{*}{$\begin{array}{l}\text { Force increment } \\
\text { during heating } \\
\text { until spalling (kN) }\end{array}$} & \multirow{2}{*}{$\begin{array}{l}\text { Extent of } \\
\text { spalling }\end{array}$} \\
\hline & & $\begin{array}{l}\text { Before } \\
\text { spalling }\end{array}$ & $\begin{array}{c}\text { After } \\
\text { spalling }\end{array}$ & & \\
\hline Test 2-5 & 63 & 54 & 52 & 54 & Minor spalling \\
\hline Test 2-6 & $\begin{array}{l}10 \\
69\end{array}$ & $\begin{array}{l}13 \\
60\end{array}$ & $\begin{array}{l}11 \\
36\end{array}$ & $\begin{array}{l}13 \\
60\end{array}$ & $\begin{array}{l}\text { Minor spalling } \\
\text { Major spalling }\end{array}$ \\
\hline Test 2-7 & 31 & 270 & 195 & 70 & Major spalling \\
\hline Test 2-8 & $\begin{array}{l}28 \\
31 \\
\end{array}$ & $\begin{array}{l}249 \\
252 \\
\end{array}$ & $\begin{array}{l}247 \\
208 \\
\end{array}$ & $\begin{array}{l}49 \\
52 \\
\end{array}$ & $\begin{array}{l}\text { Minor spalling } \\
\text { Major spalling }\end{array}$ \\
\hline Test 2-9 & \multicolumn{5}{|c|}{ No spalling } \\
\hline Test 2-10 & \multicolumn{5}{|c|}{ No spalling } \\
\hline Test 2-11 & 19 & 58 & 50 & 58 & Major spalling \\
\hline Test 2-12 & 15 & 55 & 52 & 55 & Minor spalling \\
\hline Test 2-13 & 13 & 161 & 160 & 61 & Minor spalling \\
\hline Test 2-14 & 26 & 205 & 164 & 105 & Major spalling \\
\hline Test 2-15 & \multicolumn{5}{|c|}{ No spalling } \\
\hline
\end{tabular}

457

Fig. 23 shows the evolution of the thermal expansion force for samples that had been pre-loaded. Fig. 23(a) show two cases where the heating rate (HF42 and HF60) and loading (P40 and P20) are different, but the load is applied axially. The load results in some variability on the time and thermal expansion load magnitude when spalling occurred, while the load ranges from approximately $49 \mathrm{kN}$ to $105 \mathrm{kN}$ (Table 2), most tests showed spalling within the range of 50 to $60 \mathrm{kN}$. When the load was applied eccentrically by $10 \mathrm{~mm}$ toward the heating source, no spalling was observed. The thermal expansion force in Test 2-9 and 2-10 could then fully develop for 90 minutes of heating, as shown in Fig. 23(c).

These results demonstrate that PCWs behave consistently when subjected to the same testing conditions. Consistent results were observed for the compressive load built up within restrained samples during heating and when explosive spalling occurred. Explosive spalling seemed to have a tendency to occur when the force increment due to restrained thermal expansion during heating reached about $50 \mathrm{kN}$.

\subsection{During the loading stage}

Figs. 24 and 25 show the load-displacement profiles of samples that were loaded until failure during the loading stage as soon as the heating stage ended. The start of the loading stage was fast enough to minimise the decrease in the samples' temperature. In general, all the samples behaved in a similar manner when loaded. A sample case of Test 2-5 and 2-6 is used to describe the process. Fig. 24 shows the relationship between the compressive load and the average displacement direction when a sample heated with HF42 was loaded (Tests 2-5 and 2-6). The hot load capacity for this sample was approximately $525 \mathrm{kN}$ with a corresponding axial displacement of $3.3 \mathrm{~mm}$.

Table 3 summarises the results for all tests. It can be seen that Tests 2-7 and 2-8 and Tests 2-14 and 2-15 are outliers, all the other tests have similar residual load capacity that averages $505 \mathrm{kN}$ with a standard deviation of $42 \mathrm{kN}$. After reaching the hot load capacity, these samples consistently showed brittle failure, indicating the limited contribution of the steel sheet to the performance of the PCWs. The load-displacement behaviour was generally consistent despite the different levels of spalling (minor or explosive) that occurred during heating. This means both minor and significant spalling occurrence during heating exposure could have similar effects on the load capacity after heat exposure of these samples. This similarity can be explained by the fact that the applied compressive load was significantly higher than the force due to restrained thermal deformation during heating. Therefore, despite the difference in damage levels of samples due to varied extent of spalling at lower load level, the damage would have limited influence on the load-deformation of samples at high load levels. 
The load-displacement curves for the remaining 9 tests are presented in Fig. 25. It can be seen that while ductile failure can be observed for the Tests 2-7, 2-8, 2-13 and 2-14, the brittle failure mode was exhibited by the Tests 2-9, 2-10, 2-11, 2-14 and 2-15. From Table 3, it can be established that the steel temperatures for Tests 2-7, 2-8 and 2-13 were much lower than those in Tests 2-5 to 2-10. It is likely that the steel for these tests still had sufficient influence on the failure behaviour.

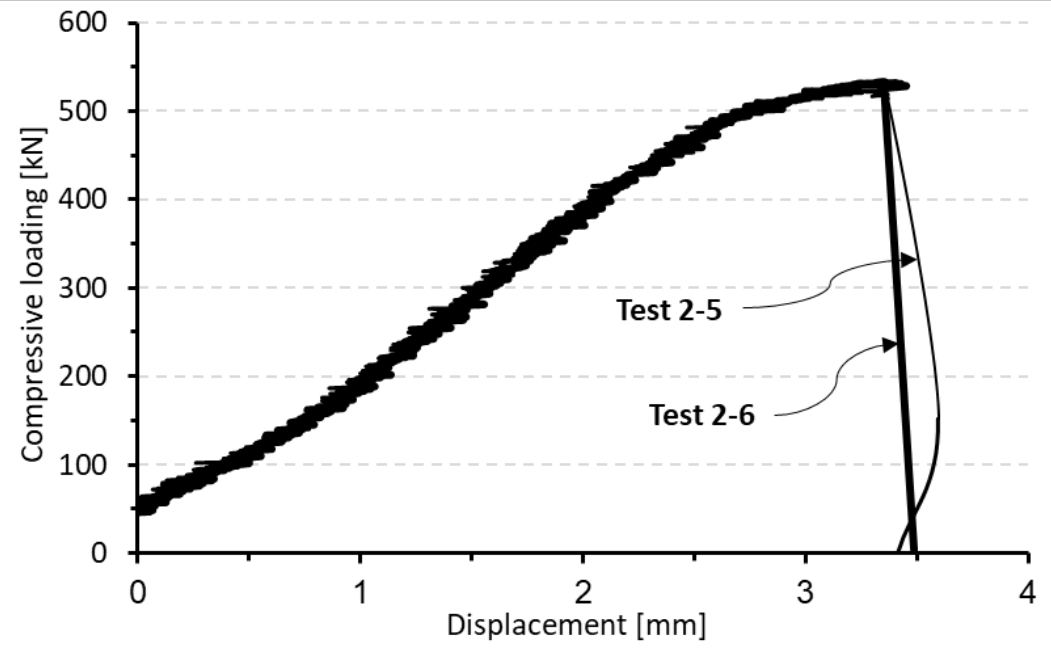

Fig. 24. Load-axial displacement behaviour of Series 2 heated samples in Test 2-5 and 2-6.

Table 3. The axial load capacities, displacement and failure modes of tested samples.

\begin{tabular}{|c|c|c|c|c|c|}
\hline Series & Sample ID & $\begin{array}{l}\text { Axial load } \\
\text { capacity } \\
\text { (kN) }\end{array}$ & $\begin{array}{l}\text { Axial } \\
\text { displacement } \\
(\mathrm{mm})\end{array}$ & $\begin{array}{l}\text { Steel } \\
\text { temperature on } \\
\text { the heated side } \\
\text { when start of } \\
\text { loading }\left({ }^{\circ} \mathrm{C}\right) \\
\end{array}$ & Failure mode* \\
\hline \multirow{15}{*}{ Series 2} & Test 2-1 & 527 & 4.03 & 25 & Ductile \\
\hline & Test 2-2 & 524 & 3.73 & 25 & Ductile \\
\hline & Test 2-3 & 513 & 3.04 & 25 & Ductile \\
\hline & Test 2-4 & 492 & 2.82 & 25 & Ductile \\
\hline & Test 2-5 & 523 & 3.32 & \multirow{2}{*}{564} & Brittle \\
\hline & Test 2-6 & 533 & 3.35 & & Brittle \\
\hline & Test 2-7 & 291 & 0.73 & \multirow{2}{*}{471} & Ductile \\
\hline & Test 2-8 & 384 & 1.24 & & Ductile \\
\hline & Test 2-9 & 503 & 1.25 & \multirow{2}{*}{564} & Brittle \\
\hline & Test 2-10 & 558 & 2.00 & & Brittle \\
\hline & Test 2-11 & 406 & 1.94 & 549 & Brittle \\
\hline & Test 2-12 & 450 & 1.95 & 538 & Brittle \\
\hline & Test 2-13 & 491 & 1.76 & 528 & Ductile \\
\hline & Test 2-14 & 366 & 1.10 & 570 & Ductile/Brittle \\
\hline & Test 2-15 & 521 & 1.49 & 686 & Brittle \\
\hline
\end{tabular}

* The failure mode is defined as brittle if the slope after failure becomes negative instantaneously, while ductile failure is defined when the slope gradually decreases to zero before becoming negative.

Among Tests 2-13 to 2-15, Test 2-14 experienced only 26 minutes of heating by HF60 that resulted in explosive spalling. The surface temperature was among the highest, and the residual load capacity was one of the lowest. The initial failure was brittle, which is consistent with samples with similar temperatures and spalling. Nevertheless, the initial brittle failure was followed by a final ductile decay. This behaviour can be explained by the contribution of the steel sheet, whose the temperature of which remained below $80^{\circ} \mathrm{C}$ (Fig. 14) during heating.

For the tests where the load was eccentrically applied (Tests 2-9 and 2-10), the samples exhibited a highly consistent load-displacement behaviour. Both samples exhibited the brittle failure mode when the 
compression load was around 500 to $550 \mathrm{kN}$. There is no clear difference between these tests and Tests 2-5 and 2-6. There were slight differences in the load-capacities between two samples ( $503 \mathrm{kN}$ and $558 \mathrm{kN}$ ), but the displacement at the maximum load-capacity was approximately double in the case of Test 2-10 (1.2 mm and $2 \mathrm{~mm}$ ).

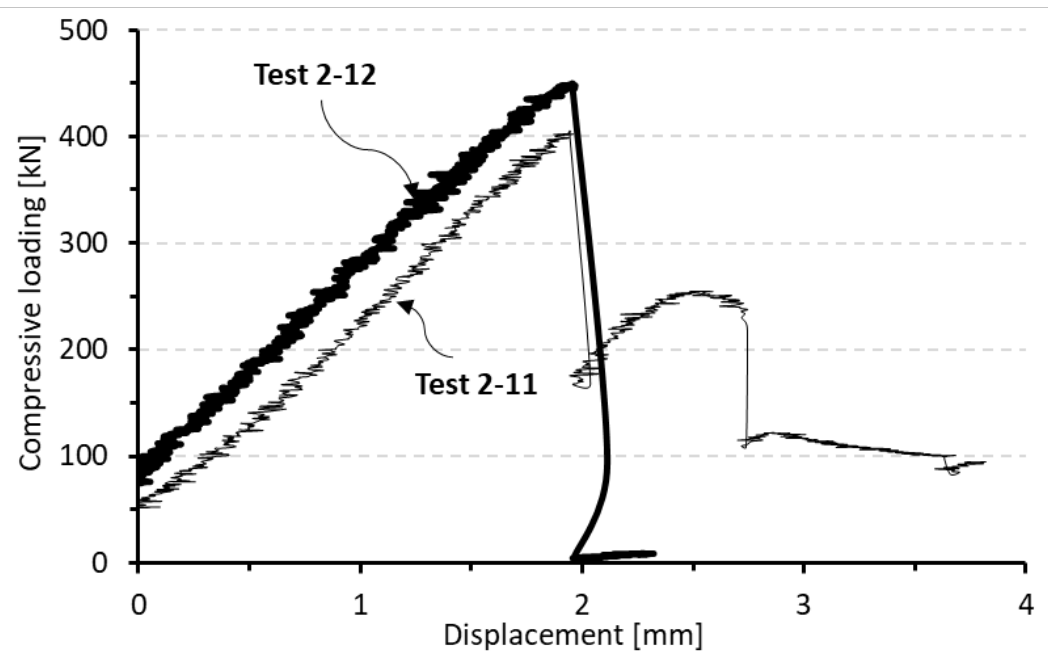

a) Samples subjected to HF60, PO, and zero eccentricity.

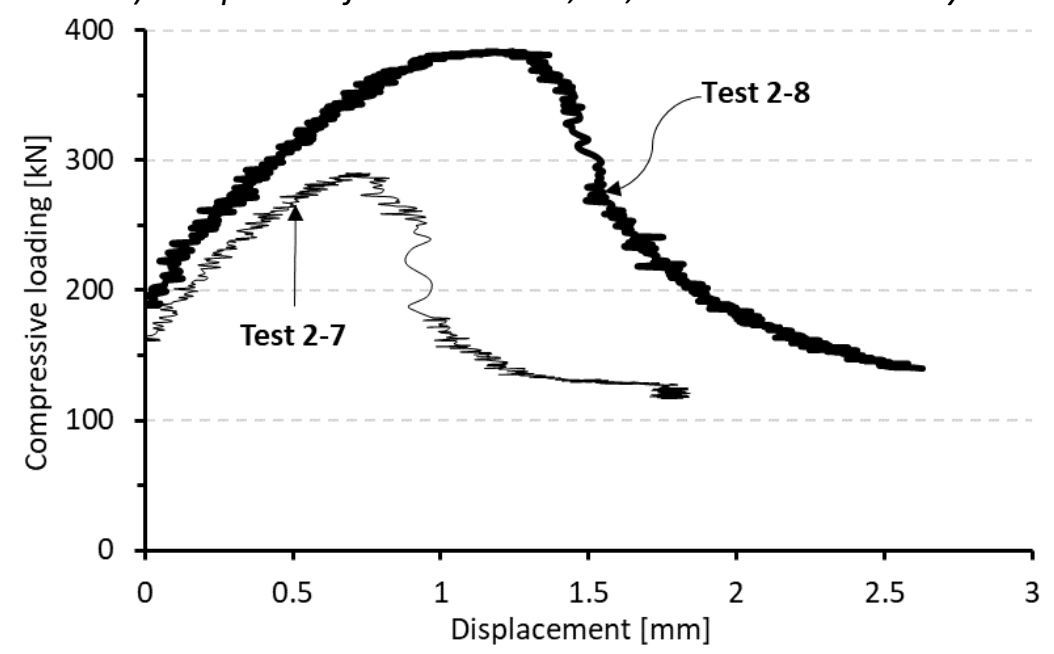

b) Samples subjected to HF42, P4O and zero eccentricity.

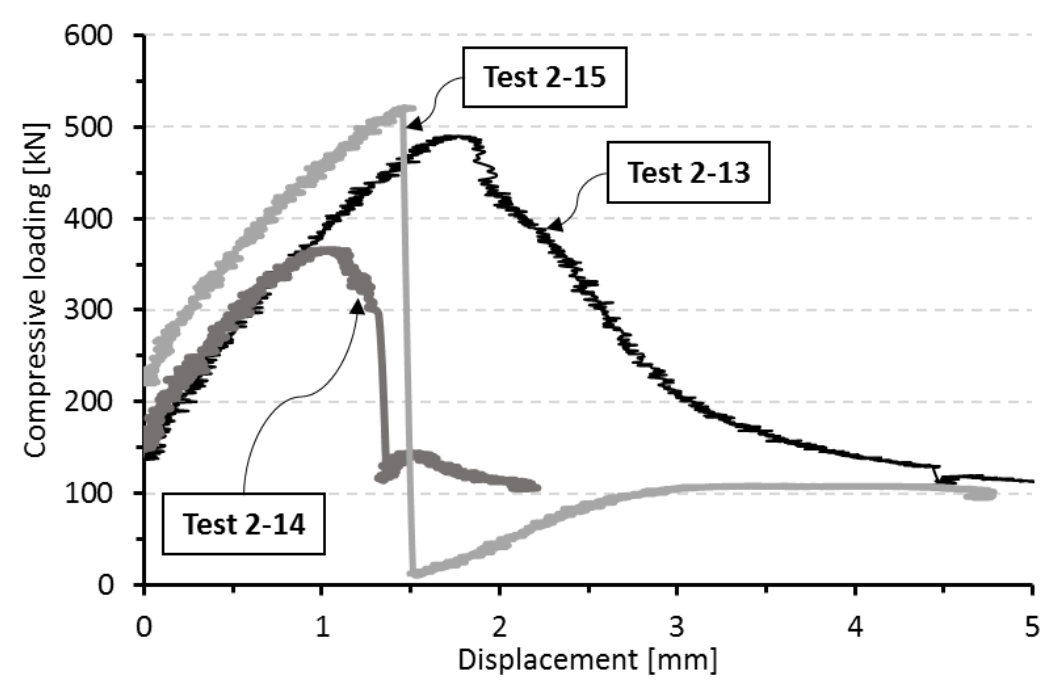

c) Samples subjected to HF60, P2O and zero eccentricity. 


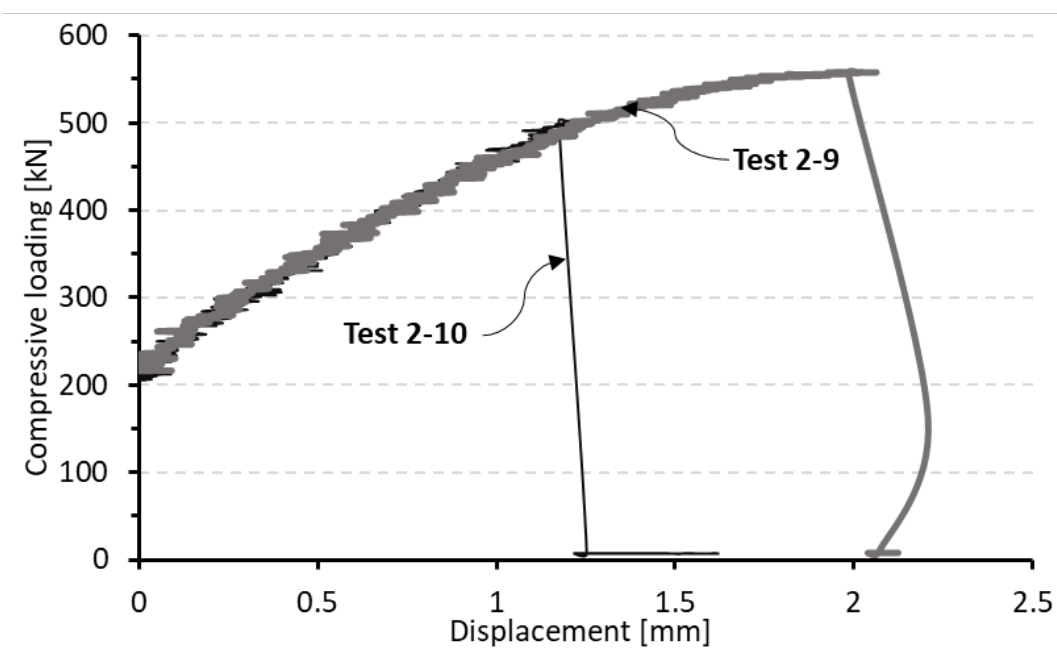

d) Samples subjected to HF42, P2O and 10-mm initial eccentricity.

Fig. 25. Load-axial displacement behaviour of Series 2 samples.
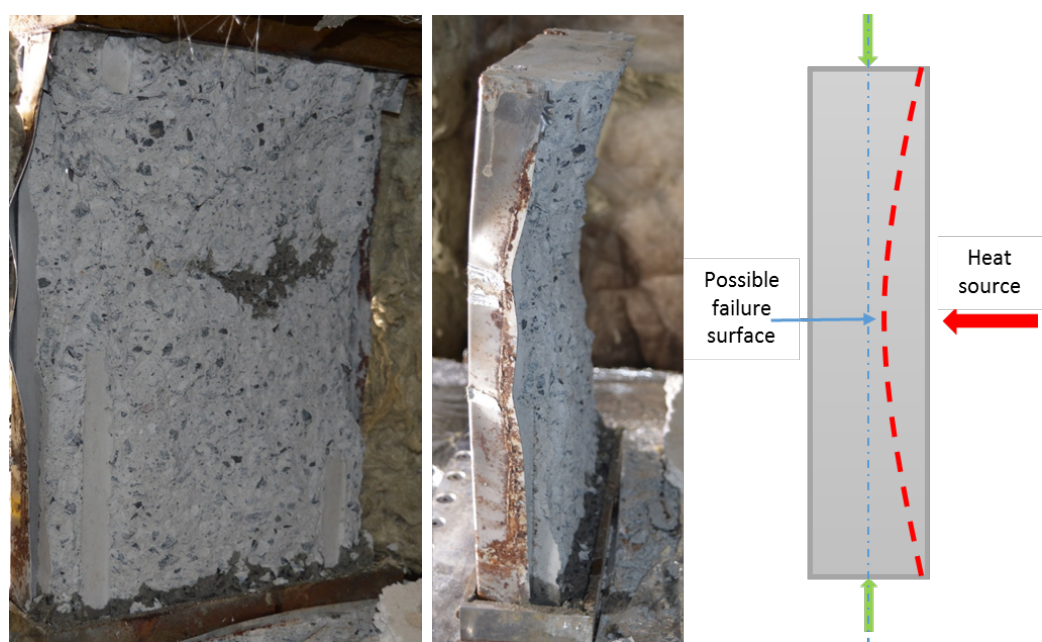

a) Failure of Series 2 samples subjected to HF42, PO and zero eccentricity.
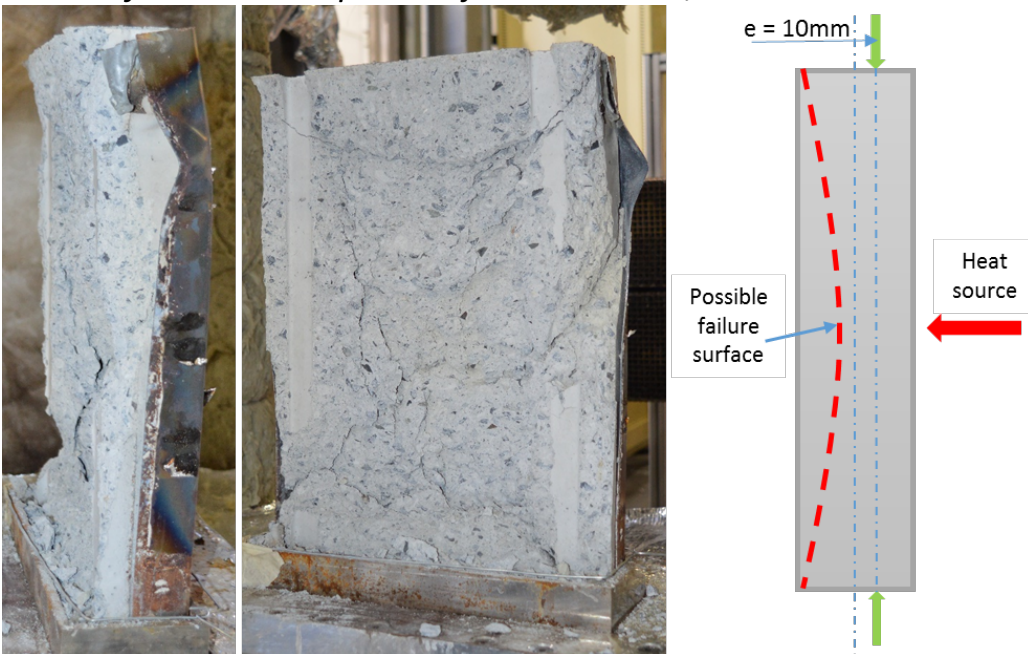

b) Failure of Series 2 samples subjected to HF42, P2O and 10-mm initial eccentricity.

Fig. 26. Failure planes of samples subjected to different thermal-mechanical load combinations.

Observation of the failed samples showed obvious and consistent modes of behaviour. All samples loaded axially exhibited a failure plane close to the heated area (Fig. 26(a)). In contrast, all samples loaded in an eccentricity manner showed the failure plane displaced towards the unheated side (Fig. 26(b)). These failure modes are distinctively different from those of the ambient temperature reference tests. At ambient temperature, the increment of the axial compressive load resulted in a symmetrical failure (Fig. 20) while the eccentricity displaced the failure towards the side where the load was applied (Fig. 21). 
The initial eccentricity of the load toward the heating source seems to have significant effects on the failure plane in the samples at high temperatures. The axially loaded samples resulted in a failure plane at the surface between the concrete and steel sheet on the heated side. This is consistent with the more significant expansion closer to the heated surface. In contrast, the eccentrically loaded samples toward the heating source showed a failure plane at the surface between the concrete and steel sheet on the unheated side. The shift of the failure plane is linked with the combined effect of the initial load eccentricity and thermal gradient within the cross-section of the sample. When subjected to a thermal gradient, the effective centroid tends to be shifted towards the colder region [23]. Thus, the eccentricity was naturally increased during heating. Consequently, the moment created by the compressive load during the loading stage was increased, and the sample was likely subject to increased bending, which resulted in tensile stresses on the unheated side of the samples. Meanwhile, the temperature gradient caused bending due to bowing [22]. Due to the large load eccentricity in this test, the bending curvature on the unheated side due to compressive load was far greater than the curvature created by the temperature gradient. Thus, the combination of these two counteracting effects resulted in the failure plane closer to the steel sheeting on the unheated side. Although the failure mode was more likely brittle for both concentrically and eccentrically loaded samples after heating, the failure plane of eccentrically loaded samples was in the opposite direction to the failure plane of the sample under concentric loading, where the effect of the temperature gradient was likely dominant.

\section{STRUCTURAL PERFORMANCE OF PCW: DISCUSSION}

At ambient condition, the results showed that the following sequence for the failure mechanism could be observed: the steel sheets buckled first, followed by the concrete core crushing. It can be clearly seen from Fig. 20 that this mechanism lead to the symmetric global buckling of the steel sheets, while Fig. $\mathbf{2 1}$ shows an unsymmetrical buckling of the steel sheet. When the samples were subjected to an eccentric load, the steel sheet closer to the load experienced local buckling, and no global buckling of the steel sheet was observed. These results are in agreement with those obtained by Wright [9], Mydin and Wang [31]. A possible explanation for the local buckling of the steel sheet is due to a high height-to-thickness ratio of $400 \mathrm{~mm}$ and $0.95 \mathrm{~mm}$ of the steel sheet. Also, local buckling tends to occur in the plate when it is fully supported, which is similar to the condition of the steel sheeting in the PCW samples. The steel sheet could not buckle inwards as it was restrained by the concrete core. Thus, only the outward buckling of the steel sheet was observed. At the onset of concrete crushing, the released energy and concrete debris caused symmetric global buckling of the steel sheets, thus split two steel sheets into opposite directions as they were not welded at the middle line (Figs. 20 and 21). A similar explanation can be used for the samples loaded eccentrically. The steel sheet in the high compressive stress region tended to be subjected to local buckling first, and the concrete in the high compressive stress region was crushed.

In terms of the axial load-axial displacement response, there is a slight discrepancy between the samples tested with different eccentricities (Fig. 19). The displacement at ultimate load capacity was smaller for the samples tested under the loading at an eccentricity of $10 \mathrm{~mm}$. The failure modes of the samples under uniaxial and eccentric load conditions were both ductile. This finding is consistent with the test conducted by Rafiei et al. [13], where mild strength steel sheets were used, leading to yielding prior buckling, and hence ductile behaviour. As can also be observed in Fig. 19, the load capacity of the samples did not drop to zero after further displacement. This behaviour proves that the steel sheets can carry loads in the post-buckling regime. This finding is in good agreement with the test results conducted by Wright [9], Mydin and Wang [31], Rafiei [32]. The axial load capacity of the sample should thereby account for the effects of both the concrete core and steel sheets.

To verify if the current analytical model can correctly capture the load capacity of PCWs at ambient and elevated temperatures, the axial load capacity of PCWs the model proposed by Uy et al. [4] is used to evaluate the load capacity of the PCW. The axial load capacity of PCWs can be calculated as:

$$
N_{u}^{a m b}=N_{u c}^{a m b}+N_{u s}^{a m b}
$$

where, $N_{u c}^{a m b}$ is the axial load capacity of the concrete portion, and $N_{u s}^{a m b}$ is the axial load capacity of the profiled steel. $N_{u c}{ }^{a m b}$ and $N_{u s}{ }^{a m b}$ can be calculated as follows: 


$$
\begin{gathered}
N_{u c}^{a m b}=k \times \sigma_{c} \times A_{c-e f f} \\
N_{u s}^{a m b}=\sigma_{s} \times A_{s-e f f}
\end{gathered}
$$

where, $\mathrm{k}=0.6-0.73$ is a correction factor for concrete stress; and $A_{c \text {-eff }}$ and $A_{\text {s-eff }}$ are the effective crosssections of the concrete core and steel sheet, respectively. The details of the effective cross-section calculations for the concrete core and steel sheets could be obtained from Uy et al. [4]. The axial load capacity of the tested samples can then be determined as:

$$
N_{u}^{a m b}=N_{u c}^{a m b}+N_{u s}^{a m b}=324+177=501 k N
$$

The load capacity and displacement in the uniaxial test $(525 \mathrm{kN}, 3.88 \mathrm{~mm}$ ) and eccentric test $(502 \mathrm{kN}, 2.93$ $\mathrm{mm}$ ) are very similar. The results show good agreement between model and experiments at ambient temperature.

At high temperature, the results showed that as the incident heat flux was increased, the axial load capacity of PCWs decreased. This finding is in agreement with reported tests with different structural elements such as columns subjected to high temperature [33]. The reduction in axial load capacity is linked to the magnitude of the temperature and temperature gradient within the cross-section. The material properties of the steel and concrete (i.e., Young's modulus, ultimate stress) are reduced with temperature increase [20]. After 1.5 hours of heating, the average temperature of the sample's cross-section reached $291^{\circ} \mathrm{C}$ for HF 42 and $342^{\circ} \mathrm{C}$ for HF60. The reduction factor for both concrete and steel at these temperatures is very close to unity, explaining why the load capacity in most of the tests remains similar to the combined load capacity of the steel and concrete at ambient (Table 3). This indicates that despite the temperature and mechanical changes, the PCWs still behave as a composite system and the model remains applicable to approximate the experimental results.

When a compressive load was applied to the samples, followed by a one-side incident heat flux, the mechanical properties of concrete and steel are unevenly reduced as a function of the temperature and its gradient $[20,27]$. As a result, the steel sheet and concrete fibres on the heated side enter the inelastic region earlier because of the presence of compressive stress. Thus, the ratio of stress to the strain of the concrete and steel is much smaller than those in the elastic region [23]. The effective centroid of the samples is therefore no longer at the same location as the geometric centroid but moves toward the colder region. The applied compressive load thus resulted in a moment that created higher compressive stress on the heated side of samples. When the compressive load is increased, the concrete and steel on the heated area are likely to fail, thus creating the failure plane closer to the heated side of the samples. The heavily loaded samples, thus, deliver the lowest load capacity. The magnitude of the load capacity is comparable to that of the concrete, showing that the composite behaviour of the PCW might have been affected.

Given the small range of incident heat fluxes $\left(42 \mathrm{~kW} / \mathrm{m}^{2}\right.$ and $\left.60 \mathrm{~kW} / \mathrm{m}^{2}\right)$, the fixed heating time of 1.5 hours, discrete initial loads and a single eccentricity, caution should be taken to extrapolate these observations to real fire conditions.

\section{CONCLUSION}

The performance of PCWs was investigated at ambient and elevated temperatures. The conclusions drawn from this experimental study can be summarised as follows:

- The PCWs exhibit the ductile behaviour at ambient temperature, but generally become more brittle at elevated temperatures;

- The increasing gap size resists the heat transfer between the steel sheet and the concrete core; the thermal resistance due to the gap is reduced when the temperature of the steel sheet increases;

- The axial load capacity of PCWs decreases with an increasing incident heat flux levels and heating time;

- The restrained condition during heating of PCWs increases the thermal expansion force developed therein, thereby increasing the possibility of explosive spalling due to thermal stresses; 
- A load eccentricity of $10 \mathrm{~mm}$ toward the heating source has insignificant effects on the axial load capacity of PCWs at ambient temperatures. However, it shifts the failure plane of the PCWs from heated side to the unheated side of the PCWs, serving as compensation to thermal bowing;

- The contribution of initially non-uniform compressive stress and temperature gradient could affect the movement of the effective centroid, thus significantly changes the failure plane of the concrete core in the PCW. The combination of load and temperature gradient should be further investigated to control the failure of the PCW at elevated temperatures.

Overall, this study demonstrates the benefits of using PCWs in building construction. The findings shed new light on the understanding and designing these types of structural elements at both ambient and high temperatures. A limitation of this study is that the effects of intermediate fasteners, which are used in practical design, have not been investigated. Also, the tests with an eccentric load, even if the impact at ambient temperature is negligible, highlight how the eccentricity compensates thermal bowing. Thus, a more extensive study that includes a broader range of incident heat fluxes, as well as the direction and eccentricity of the initial compressive load, should also be investigated. A further study could also assess the length of the heating time, and the magnitude and eccentricity of the initial compressive load. Despite the inevitable limitations of an experimental study of this nature, the data collected from this test offers insight into the development of double-skin composite structures.

\section{ACKNOWLEDGEMENTS}

The authors gratefully acknowledge the financial support of the Australian Research Council through LP140100504 and DP150102354 grants. The first author acknowledges the excellent assistance of Mr Chris Russ to prepare the water-cooled system and spherical heads using for the $1 \mathrm{MN}$ MTS machine, and the generous help of $\mathrm{Mr}$ Shane Walker to prepare the samples. The first author also acknowledges the financial support from his supervisors and from University College London to conduct a short-term visit at the Department of Civil, Environmental and Geomatic Engineering.

\section{REFERENCES}

1. Wright, H., K. Hossain, and S.C. Gallocher, Composite walls as shear elements in tall structures, in Structures Congress XII: Proceedings of papers presented at the structures congress '94, Baker N. C. and Goodno B. J., Editors. 1994, The structural division of the American Society of Civil Engineers: Atlanta, GA. p. 140-145.

2. Wright, H.D. and S.C. Gallocher, The behaviour of composite walling under construction and service loading. Journal of Constructional Steel Research, 1995. 35(3): p. 257-273.

3. Hilo S. J., et al., A state-of-the-art review on double-skinned composite wall systems. Thin-Walled Structures, 2015. 97: p. 74-100.

4. Uy, B., H. Wright, and M.A. Bradford, Combined axial and flexural strength of profiled composite walls, in Proceedings of the Institution of Civil Engineers - Structures and Buildings. 2001.

5. Prabha, P., et al., Effect of confinement on steel-concrete composite light-weight load-bearing wall panels under compression. Journal of Constructional Steel Research, 2013. 81: p. 11-19.

6. Wright, H.D., T.O.S. Oduyemi, and H.R. Evans, The experimental behaviour of double skin composite elements. Journal of Constructional Steel Research, 1991. 19(2): p. 97-110.

7. Wright, H.D. and K.M.A. Hossain, In-plane shear behaviour of profiled steel sheeting. Thin-Walled Structures, 1997. 29(1): p. 79-100.

8. Bradford, M.A. and H.D. Wright, Time-dependent local buckling in thin-walled lightweight composites. Journal of Constructional Steel Research, 1998. 46(1-3): p. 221.

9. Wright, H., The axial load behaviour of composite walling. Journal of Constructional Steel Research, 1998. 45(3): p. 353-375.

10. Hossain, K. and H. Wright, Performance of profiled concrete shear panels. J. Struct. Eng., 1998. 124(4): p. 368-381.

11. Hossain, K. and H. Wright, Shear interaction between sheeting and concrete in profiled composite construction, in Australasian Structural Engineering Concrete. 1998: Auckland. 
12. Wright, H., Axial and bending behavior of composite walls. Journal of Structural Engineering, 1998. 124(7): p. 758-764.

13. Rafiei, S., et al., Profiled sandwich composite wall with high performance concrete subjected to monotonic shear. Journal of Constructional Steel Research, 2015. 107: p. 124-136.

14. Taormina, A. and K.M.A. Hossain, Behaviour of profiled composite walling system under elevated temperatures, in Annual Conference of The Canadian Society for Civil Engineering 2012 : Leadership In Sustainable Infrastructure, CSCE, Editor. 2012, Canadian Society for Civil Engineering Montreal: Edmonton, Alberta, Canada.

15. Hilo S. J., et al., Axial load behavior of a composite wall strengthened with an embedded octagon cold-formed steel. Applied Mechanics and Materials, 2015. 754-755: p. 437-441.

16. Hu, S. and K.G. Nicholls, Regulatory Information Report: An assessment of the fire resistance performance of $51 \mathrm{~mm}, 64 \mathrm{~mm}$ and $78 \mathrm{~mm}$ thick vertically orientated Speedpanel wall systems if tested in accordance with AS1530.4-2005. 2015, Exova Warringtonfire Aus Pty Ltd.

17. Ding, J. and Y.C. Wang, Realistic modelling of thermal and structural behaviour of unprotected concrete filled tubular columns in fire. Journal of Constructional Steel Research, 2008. 64(10): p. 10861102.

18. Ghojel, J., Experimental and analytical technique for estimating interface thermal conductance in composite structural elements under simulated fire conditions. Experimental Thermal and Fluid Science, 2004. 28(4): p. 347-354.

19. Rush, D., Fire performance of unprotected and protected concrete filled steel hollow structural sections, in School of Engineering. 2013, The University of Edinburgh: Edinburgh, UK.

20. European Standard, Eurocode 2: Design of concrete structures. ENV 1992: Part 1-2: General rules Structure fire design, in EN 1992-1-2 (2004): Eurocode 2: Design of concrete structures - Part 1-2: General rules - Structural fire design. 2004, European committee for Standardization: Brussiles, Belgium.

21. Le, Q.X., J.L. Torero, and V.T.N. Dao, Understanding the effects of stress on the coefficient of thermal expansion. International Journal of Engineering Science, 2019. 141: p. 83-94.

22. Usmani, A.S., et al., Fundamental principles of structural behaviour under thermal effects. Fire Safety Journal, 2001. 36(8): p. 721-744.

23. Garlock, M. and S. Quiel, Mechanics of wide-flanged steel sections that develop thermal gradients due to fire exposure. Int J Steel Structural, 2007. 7: p. 153-162.

24. Standards Australia, AS 1012.1:2014: Methods of testing concrete. Method 1: Sampling of concrete. 2014, Standards Australia Limited: Sydney, NSW 2001, Australia.

25. Standards Australia, AS 1012.2:2014: Methods of testing concrete. Methods 2: Preparing concrete mixes in the laboratory. 2014, Standards Australia Limited: Sydney, NSW 2001, Australia.

26. Maluk, C., et al., A heat-transfer rate inducing system (H-TRIS) test method. Fire Safety Journal, 2016.

27. Le, Q.X., et al., Effects of temperature and temperature gradient on concrete performance at elevated temperatures. Advances in Structural Engineering, 2018. 21(8): p. 1223-1233.

28. Le, D.B., et al., Application of digital image correlation system for reliable deformation measurement of concrete structures at high temperatures. Engineering Structures, 2019. 192: p. 181-189.

29. Welch, S., et al., BRE large compartment fire tests-Characterising post-flashover fires for model validation. Fire Safety Journal, 2007. 42: p. 548-567.

30. Khoury, G.A., Effect of fire on concrete and concrete structures. Progress in structural engineering and materials, 2000. 2(4): p. 429-447.

31. Mydin, M.A.O. and Y.C. Wang, Structural performance of lightweight steel-foamed concrete-steel composite walling system under compression. Thin-Walled Structures, 2011. 49(1): p. 66-76.

32. Rafiei, S., Behaviour of double skin profiled composite shear wall system under in-plane monotonic, cyclic and impact loadings. 2011, ProQuest Dissertations Publishing.

33. Lie, T.T. and T.D. Lin, Fire performance of reinforced concrete columns, in Fire Safety: Science and Engineering: ASTM STP 882, T.Z. Harmathy, Editor. 1985, American Society for Testing and Materials: Philadelphia. p. 176-205. 